\title{
Population Genetics of a Reintroduced Fisher (Pekania pennanti) Population in West Virginia
}

\author{
Caroline E. Harms \\ West Virginia University, ceh0038@mix.wvu.edu
}

Follow this and additional works at: https://researchrepository.wvu.edu/etd

Part of the Bioinformatics Commons, Genetics Commons, Terrestrial and Aquatic Ecology Commons, and the Zoology Commons

\section{Recommended Citation}

Harms, Caroline E., "Population Genetics of a Reintroduced Fisher (Pekania pennanti) Population in West Virginia" (2021). Graduate Theses, Dissertations, and Problem Reports. 7999.

https://researchrepository.wvu.edu/etd/7999

This Thesis is protected by copyright and/or related rights. It has been brought to you by the The Research Repository @ WVU with permission from the rights-holder(s). You are free to use this Thesis in any way that is permitted by the copyright and related rights legislation that applies to your use. For other uses you must obtain permission from the rights-holder(s) directly, unless additional rights are indicated by a Creative Commons license in the record and/ or on the work itself. This Thesis has been accepted for inclusion in WVU Graduate Theses, Dissertations, and Problem Reports collection by an authorized administrator of The Research Repository @ WVU. For more information, please contact researchrepository@mail.wvu.edu. 
Population genetics of a reintroduced fisher (Pekania pennanti) population in West Virginia

\author{
Caroline Harms
}

\begin{abstract}
Thesis submitted to the
Davis College of Agriculture, Natural Resources and Design at

West Virginia University
\end{abstract}

\begin{abstract}
in partial fulfillment of the requirements for the degree of
Master of Science in

Wildlife and Fisheries Resources
\end{abstract}

\author{
Amy B. Welsh, Ph.D. \\ John W. Edwards, Ph.D. \\ Rich E. Rogers, M.S. \\ Division of Forestry and Natural Resources
}

\title{
Morgantown, WV
}

2021

Keywords: population genetics, reintroduction, translocation, furbearer, Pekania [Martes] pennanti

Copyright 2021 Caroline Harms 


\section{ABSTRACT \\ Population genetics of a reintroduced fisher (Pekania pennanti) in West Virginia}

\section{Caroline Harms}

ABSTRACT Fishers (Pekania pennanti) were reintroduced in West Virginia in 1969 with no population wide genetic analysis ever having been conducted. Genetic analysis of reintroduced populations is vital to assess genetic diversity as an indicative of population viability. My objective was to collect fisher samples throughout West Virginia, nearby states where fisher may be migrating (PA and NY), and the New Hampshire source population to provide a full genetic interpretation of the reintroduced West Virginia population. Genetic analysis was used to measure genetic diversity, admixture or delineation of subpopulations, and effective population size. Sample location and genetic data were combined to assemble population-based maps for the population, revealing possible migration routes between individuals and subpopulations. Due to the small number of individuals that were released during reintroduction into West Virginia $(n=23)$, we predicted effects of low genetic diversity. Genetic analysis revealed distinct genetic populations $(\mathrm{K}=3)$ across WV, PA, NY and NH. There were also distinct populations $(\mathrm{K}=3)$ within the state of West Virginia. These three populations support contemporary evidence of historic reintroductions in West Virginia and Pennsylvania and the possibility of a relict population remaining in West Virginia. The effective population size for West Virginia $\left(\mathrm{N}_{\mathrm{e}}=94\right)$ was comparable to neighboring Pennsylvania $\left(\mathrm{N}_{\mathrm{e}}=108\right)$, even though West Virginia has shown evidence of a recent bottleneck. Allelic richness was not different across all four states. Relatively low heterozygosity was found in the West Virginia population $\left(\mathrm{H}_{\mathrm{e}}=0.560\right)$ compared to the source population $\left(\mathrm{H}_{\mathrm{e}}=0.623\right)$, thus an effort to add genetic diversity through additional translocations from different sources may be necessary. 


\section{ACKNOWLEDGEMENTS}

I would like to acknowledge my graduate committee, Dr. Amy Welsh, Dr. John Edwards, and Rich Rogers for their guidance, expertise, and resilience. I would also like to thank Dr. Chris Ryan for all the help connecting with trappers for my sample collection in this study. Thank you to all the West Virginia trappers and managers from the West Virginia Division of Wildlife and Natural Resources for providing samples from their harvest. Without their passion and recreation for trapping furbearers in the state, I would not have been able to conduct this study. Thank you to Dr. Jeffery Larkin of Indiana University of Pennsylvania and Matthew Lovallo of Pennsylvania Game Commission for providing a breadth of my dataset. I want to acknowledge Brin Kessinger, Mary Akers, Lucas Price, Yvette Halley, and Cassia Busch from the Wild Genomics lab for their invaluable help and guidance in the lab. I would like to bring special attention to Brin Kessinger, who was my biggest support and unwavering friend during my time at West Virginia University, you will be missed. I want to thank Kirsten Belcher, my fellow graduate student by my side in furbearer research and friendship. Additionally, thank you to all the Division of Forestry and Natural Resources graduate students at WVU for your accepting and supporting me in your community. Finally, I want to thank my family, I can attribute all my achievements to the support and encouragement of my parents Chris and Mary Harms.

I would like to acknowledge my funding sources, the West Virginia Division of Natural Resources. I want to thank the WVU Genomics Core Facility, Morgantown, WV for the laboratory support needed to conduct my thesis. 


\section{TABLE OF CONTENTS}

ABSTRACT.

ACKNOWLEDGMENTS ...................................................................ii

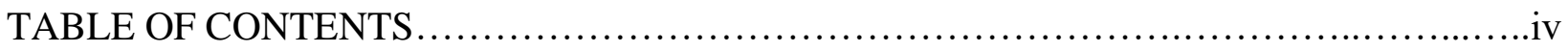

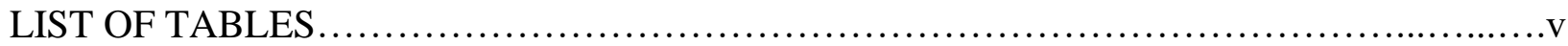

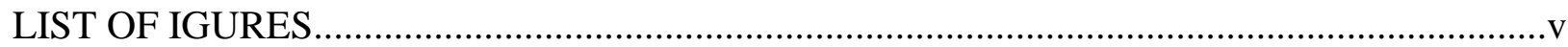

Chapter 1: Introduction and Literature Review......................................................................

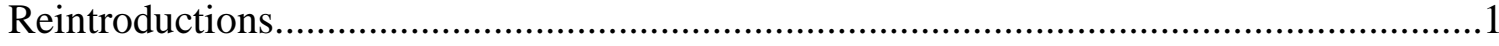

Fisher (Pekania pennanti) ............................................................................................

Genetic Monitoring of Reintroduced Populations..........................................................10

Thesis Objectives................................................................................................11

Chapter 2: Contemporary Population Structure: Reintroduction or Recolonization?....................14

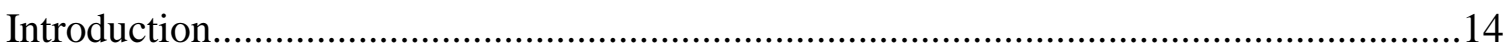

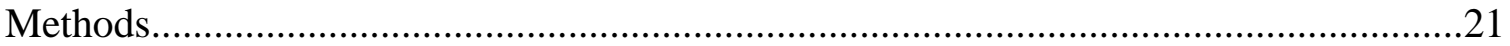

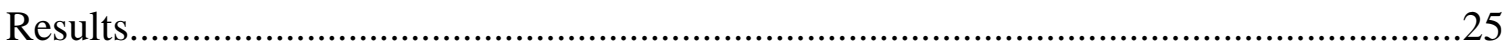

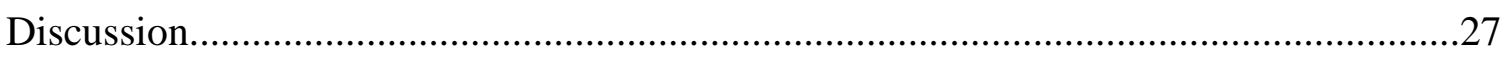

Chapter 3: Maximizing Genetic Diversity of Reintroduction Events............................................33

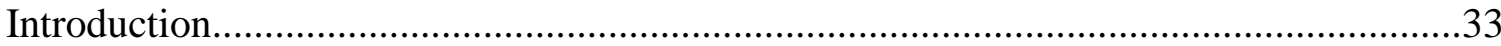

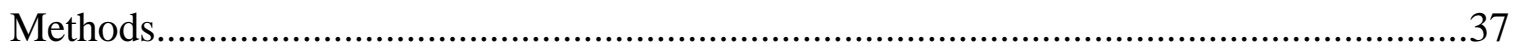

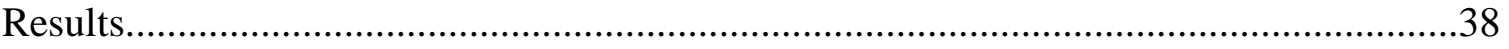

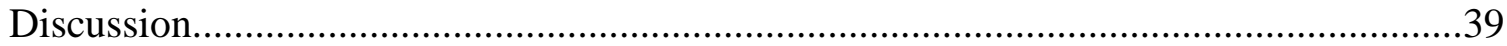

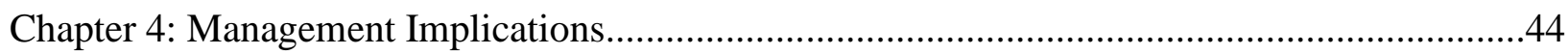

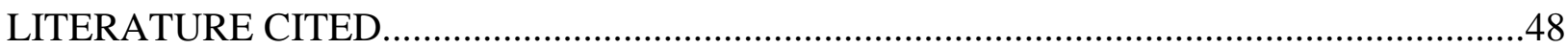

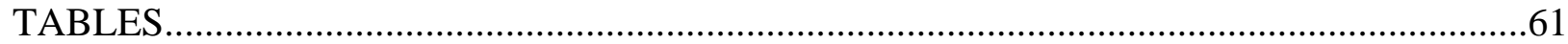

FIGURES 


\section{LIST OF TABLES}

Table 1. Percentages of admixture per population when measured as 0.8 or higher (A, B, C), and any sample measuring under 0.8 , admixture measured as the next top two populations $(\mathrm{AB}, \mathrm{BC}, \mathrm{AC})$.

Table 2. FST pairwise analysis of sample populations from 4 geographically inferred fisher populations. Shaded cells indicate associated p-values with an alpha of 0.05. Significance denoted with “*”. Values above the diagonal are the FST values, and values below the diagonal are associated $\mathrm{p}$-values (alpha $=0.05$ ).

Table 3. Genetic diversity measured as observed heterozygosity $\left(\mathrm{H}_{\mathrm{O}}\right)$ and expected heterozygosity $\left(\mathrm{H}_{\mathrm{E}}\right)$ per locus per state population from program GENEPOP. Locus results with (*) indicate the locus is out of Hardy-Weinberg Equilibrium (HWE). Allelic richness (A) per locus and population based on minimum sample size of 8 diploid individuals from program GENEPOP.

Table 4. Effective population size $\left(\mathrm{N}_{\mathrm{e}}\right)$ for each state and relative sample sizes (n) reported from linkage disequilibrium estimation at a lowest allele frequency of 0.02 with $95 \%$ confidence intervals (CI).

\section{LIST OF FIGURES}

Figure 1. West Virginia county map representing the cumulative number of fishers harvested by WV trappers by county from 1972 to 2021. Sourced from West Virginia Division of Natural Resources (WVDNR).

Figure 2. Graphic representation of estimated probability of data for each $\mathrm{K}$ value. A) Logarithm probability of $\mathrm{K}$ within WV samples and C) across all samples (WV, PA, NY, NH) together. B) Delta K within WV samples and D) across all samples. 
Figure 3. Individual memberships to identified clusters based on genetic data. A) Results from all four states (WV, PA, NY, NH) based on $\mathrm{K}=3$. B) Results limited to only WV samples based on $\mathrm{K}=3$.

Figure 4. ArcGIS Pro map of all samples with location information $(n=459)$. Colored dots represent population percentage results from STRUCTURE. Samples were given population A (red), B (green), or C (blue) based on the highest population percentage of the three possible populations.

Figure 5. ArcGIS Pro map of West Virginia samples with location information $(n=87)$. Colored dots represent population percentage results from STRUCTURE. Samples were given population A (pink), B (green), or C (light blue) based on the highest population percentage of the three possible populations.

Figure 6. ArcGIS Pro map of all samples with location information $(n=459)$. Colored circles represent admixture population percentage results from STRUCTURE. Samples were given pure population A (red), B (yellow), or C (blue) based on $>0.8$ population percentage of the three STRUCTURE populations. Samples with $<0.8$ percentage were given combined of top two percentage represented as squares with $\mathrm{AB}$ (orange), $\mathrm{BC}$ (green), or AC (purple).

Figure 7. Graphic results of a Principal Coordinates Analysis (PCoA) from the GenAlEx package for Microsoft Excel. The principal coordinates optimize the representation of the squared pairwise distances between individuals A) across all states and B) within WV. 
Figure 8. Graphic results of a Principal Coordinates Analysis (PCoA) from the GenAlEx package for Microsoft Excel. The principal coordinates optimize the representation of the squared pairwise distances between sexes (Female or Male) within A) Pennsylvania B) West Virginia. 


\section{Chapter 1: Introduction and Literature Review \\ Reintroductions}

Reintroductions are widely implemented for wildlife management efforts. A reintroduction is the intentional movement and release of a species of interest within the historical range to an area from which the species was extirpated. The use of reintroductions as a management tool has been steadily increasing, which reflects the confidence in this technique among wildlife conservation efforts (Stewart et al. 2017). Although management-based reintroductions have been occurring for over a century, effective planning and success assessment techniques have recently been developed and utilized (Seddon et al. 2007). A postrelease reintroduction program to gauge success or failure should include monitoring of demographic performance, behavior, ecology, mortality, and genetics (IUCN 1995). Researchers and managers typically deem a reintroduction an overall success once the population is selfsustaining or reestablished (Stewart et al. 2017; Lewis et al. 2012).

Historically, reintroductions occurred as “one-off” management with little to no monitoring or research objectives (Ewen and Armstrong. 2007). These unmonitored reintroductions often had poor success rates according to a survey of bird and mammal reintroductions from 1973 to 1986 (Griffith et al. 1989). This survey found only $27 \%$ of the reporting agencies for these reintroductions had any protocols in place to assist in monitoring success or failure of the reintroduction. While evaluating 80 threatened, endangered, or sensitive species translocations during this time, only $44 \%$ were considered successful. In this study, translocations were considered successful if it resulted in a self-sustaining population. The likelihood of success increased when large numbers of individuals were released, and habitat was high quality (Griffith et al. 1989). 
Continued monitoring and periodic reassessment are vital to ensure that management decisions will not be made on outdated or incomplete assumptions of population structure, which may lead to ineffective management strategies (Greenhorn et al. 2018). A robust scientific framework should be adopted to avoid the incorrect guesswork that doomed many reintroductions (Ewen and Armstrong. 2007). An example of such comes from an experimental study of the translocation of noisy miners (Manorina malencephala) in which researchers assumed introduced individuals would assimilate with resident populations based on where they were released. Instead, the released individuals traveled much farther than their assumed home range, which violated the assumption that one release group did not influence how another group behaved (Clarke and Schevdin. 1996). In recent years, genetic monitoring has become one of the most useful tools for monitoring elusive, small and/or endangered populations. Using population genetics, researchers can investigate demographic and genetic parameters and effectively quantify their changes for a given population (De Barba et al. 2010). These genetic assessments can be key in determining the success or progress of a reintroduction project. When populations are small, they become susceptible to extinction via demographic stochasticity, inbreeding and environmental fluctuations (Komers and Curman 2000). We know that populations tend to lose diversity if a small number of individuals are used as founders for reintroductions.

Numerous techniques can be used for genetic assessments of reintroduced species. Ideally, DNA samples from the original source population should be compared to samples from a successfully established reintroduced population to determine if changes in genetic structure have occurred (Williams et al. 2000; Hapeman et al. 2017). When source population DNA is not available, focus turns solely to the reintroduced population for genetic assessment. Reintroduced populations tend to start at relatively low densities and are therefore at risk of genetic diversity 
loss through genetic bottlenecks and drift. Once establishment occurs following a reintroduction, rapid changes to population genetics may result (Greenhorn et al. 2018). However, following reintroduction, gene flow often increases due to higher connectivity with adjacent populations, leading to increased genetic diversity and genetic homogenization (Excoffier et al. 2009). To assist in determining fisher genetic health and future viability of the population, I will be evaluating the present genetic status of the fisher (Pekania pennanti) population since their reintroduction to West Virginia in 1969.

\section{Fisher (Pekania pennanti)}

The fisher is a mid-sized mustelid carnivore native to North America, historically established in the northern United States and extending well into Canada. Fisher populations were first documented during European settlement and range was determined to also extend south along the Appalachian and Pacific coast mountains. Specifically, the northern limit was considered $60^{\circ} \mathrm{N}$ as well as the latitude west of Hudson Bay and the latitude east of the southern tip of James Bay (Powell and Zielinski 1994). Habitat types occupied by fisher vary across eastern, midwestern and western populations. They occupy second growth forests with dense canopy cover that can include dense lowland, spruce-fir, northern-conifer, mixed-conifer and northern-hardwood forests (Powell and Zielinski 1994).

Fisher populations saw a decline in the early 1900's following unregulated and excessive harvest, compounded by habitat loss and fragmentation (Greenhorn et al. 2018; Linden et al. 2017; Williams et al. 2000). Trapping restrictions, harvest management and forest rehabilitation occurring in the 1950's began to reverse declines in fisher populations (Greenhorn et al. 2018). At this time, natural recolonization of fisher occurred, expanding some Canadian fisher 
populations (Carr et al. 2007). In addition, known remnant populations of fisher existed in the Adirondack Mountains of New York, the White Mountains of New Hampshire, the Moose Plateau of Maine, the Big Bog area of Minnesota, as well as New Brunswick (Canada), Algonquin Provincial Park (Canada), and Chapleau Game Preserve (Canada) (Carr et al. 2007; Hapeman et al. 2017; Greenhorn et al. 2018). After natural recolonization and reintroductions, fisher have been able to recover in parts of their historic range, such as eastern North America and Montana; however, many populations remain absent or fragmented in the Pacific northwest and south of the Great Lakes (Lewis et al. 2012, Williams et al. 2006).

History of P. pennanti in West Virginia

In West Virginia, fishers were considered rare by the turn of the $19^{\text {th }}-20^{\text {th }}$ century. Though reports of trapped fishers and pelt trade were reported from the 1870's, West Virginia considered fisher rare or extirpated by 1912 (Lesser and Cromer 2015). The first and only reported effort to translocate and reintroduce fishers to West Virginia occurred during the winter of 1969. During this translocation, 23 fishers were moved from a source population in New Hampshire and released in two sites where fisher had been known to be abundant in West Virginia: Canaan Mountain in Tucker County, WV and Cranberry Glades in Pocahontas County, WV (Lesser and Cromer 2015). Tucker County received 15 individuals and Pocahontas county received 8 individuals. Reports from managers indicated that expansion of fisher from the Tucker Co. release occurred well into the Monongalia National Forest whereas expansion was not seen from the Pocahontas release site (Cromer 2002). Today's fisher population in West Virginia is considered directly sourced from the New Hampshire population, with assumed natural recolonization occurring via bidirectional migration from neighboring states (MD, PA, VA), specifically migration between a reintroduced/translocated Pennsylvania population that 
received their individuals from both New Hampshire and New York in 1994-1998 (Lewis et al 2012).

According to the West Virginia Division of Natural Resources (WVDNR), the fisher population has slowly and steadily increased since the 1969 reintroduction. Unlike most reintroductions that protect the new individuals from legal harvest to give them time to establish or assimilate, West Virginia trappers could harvest one fisher per year the first year after release. This was considered sustainable due to the higher difficulty of trapping fisher compared to other furbearers in the state. The WVDNR predicts there is a population of 1,000-2,000 individuals in the forested parts of the state (personal communication, Rich Rogers, WVDNR). While reports of fisher sightings have occurred throughout the state since the release, harvest reports indicate densities highest along the northern Allegheny Mountain and eastern panhandle ridge and valley counties and along the Pennsylvania and Maryland borders (Figure 1). Reports of fisher abundance were in red spruce forests of higher elevation areas of the eastern mountainous counties of West Virginia (Cromer 2002).

The reintroduced population in West Virginia has previously and briefly been evaluated to determine reintroduction success (Stewart et al 2017; Williams et al. 2000, Williams et al. 1999). Williams et al. (2000) examined four successful fisher reintroductions, including the one in West Virginia. This study collected 18 fisher samples from the state and analyzed 20 allozyme loci, with results of 1.2 alleles/locus, 0.038 heterozygosity/locus and 0 unique alleles. The range for all 8 states in the study is 1.2 to 1.8 alleles/locus and $0.027-0.090$ heterozygosity/locus. Differences in allele frequencies were observed between New Hampshire (source population) and West Virginia $\left(\mathrm{X}^{2}=18.02, \mathrm{df}=6, \mathrm{P}<0.006\right)$. 
Williams et al. (2000) also conducted pairwise comparisons between New Hampshire and West Virginia with a mean $f$ (correlation of genes within individuals within populations) $=0.378$, mean $\mathrm{F}$ (correlation of genes within individuals; inbreeding) $=0.425$ and mean $\theta$ (correlation of genes of different individuals in the same population; coancestry) $=0.076$, with both mean $f$ and mean F having a $\mathrm{P}<0.05$ (Weir and Cockerham.1984). Interestingly, they found alleles that were high in frequency in West Virginia were rare or absent in the New Hampshire population.

An earlier genetic study of this same population occurred during the West Virginia trapping season of 1996-1997 and was also based on outdated allozyme evaluation techniques (Williams et al. 1999). They measured genetic polymorphisms in the species and included New Hampshire and West Virginia samples measured across 30 loci, with no direct comparisons made between these two populations. While the Stewart et al. (2017) study revisited fisher reintroductions across North America, the only reference to West Virginia's reintroduced population came from their interpretation of the Williams et al. (1999) study. Williams et al. (1999) states that the New Hampshire source population had an "ambiguous" (a term used in this study that cannot confirm the strength of relatedness) contribution of reintroduced individuals to the contemporary West Virginia genetic population.

\section{History of P. pennanti in Pennsylvania}

Pennsylvania has a similar history of extirpation of fisher in the state. The date when fisher were considered extirpated has not been clearly established, but it occurred in the early $20^{\text {th }}$ century. Pennsylvania's modern fisher population was established after 30 fisher were translocated from the Adirondacks in New York in 1979 into northern counties as well as natural colonization from the 1969 reintroduction in West Virginia into southern counties (PGA 2016). Additionally, Pennsylvania experienced a regeneration of 6.5 million ha of forest habitat, 
providing good habitat for the fisher. The state conducted another reintroduction during 19941998 by translocating 190 fisher from New York and New Hampshire source populations (Larkin et al. 2010). Today's Pennsylvania populations are considered established in central, northern and southwestern areas of the state with a record 503 fisher harvested during the 20152016 trapping season (PGA 2016, Williams et al. 2000).

Genetic studies have been conducted on the Pennsylvania fisher population, revealing the West Virginia fisher expanding to southcentral and southwestern Pennsylvania (Larkin et al. 2011, Ellington 2010). This was a result of 359 Pennsylvania fisher samples tested from 20062014, which laid out geographically the presence of two populations: "north" (New York sourced genetics) and "south" (West Virginia sourced genetics) across the state of Pennsylvania. Both New York and West Virginia fisher samples were included in this study to determine the genetics of both subpopulations. There was evidence of admixture of these subpopulations where they overlap in central Pennsylvania. Historic genetic data of the state's population collected during 2011-2015 found admixture between Pennsylvania and West Virginia populations in the south and admixture between Pennsylvania and New York in the northeast of the state.

\section{History of P. pennanti in New Hampshire}

New Hampshire's estimated fisher population size has oscillated over time but has provided numerous individuals for reintroductions or augmentations in other states since the mid-twentieth century (Lewis et al. 2012). Like other states, New Hampshire's fisher population was near extinction due to habitat loss and unregulated trapping. In recent years, trapper harvest reports indicate the population may be increasing. Recently, the state's wildlife biologists reported that densities fluctuate cyclically every 15 years but no density estimate currently exists. 
State biologists consider several factors such as natural population dynamics, environmental changes or competition influencing changes in the population (Keating 2017).

History of P. pennanti in New York

Similar to New Hampshire, New York's fisher numbers have fluctuated throughout the centuries. Range was restricted to only the Adirondack Mountains by the mid-1930's. Similar to other areas, fisher declines in New York were a result of unregulated trapping and large-scale declines in suitable habitat due to fires, agricultural practices and timber harvesting (NYSDEC 2015). New York protected their remaining fisher with limited harvest since 1937 (Saunders 1988). Fisher from the Adirondacks were translocated to the Catskills of New York in the 1970s (Stuhmiller 2010). While reports from the early 2000's indicate an overall increasing fisher population, there is evidence of a possible decline from the Adirondacks region while concurrently an expansion of fisher range into the Southern Zone (SZ) portion of New York. As of 2015, the Adirondack Wildlife Management Unit (WMU) fisher population ranges from 3,800-5000 fisher (NYSDEC 2015).

\section{Genetic Structure of Reintroduced P. pennanti populations}

Fisher are one of the most frequently and successfully reintroduced carnivore species in North America (Lewis et al. 2012, Drew et al. 2003). Since the first successful fisher reintroduction in Nova Scotia in 1947, there have been over 17 fisher reintroductions or translocations in North America, with more than 1000 individuals released (Williams et al. 2000). Fisher translocations across North America have occurred to augment or reintroduce fisher populations within their historical native range (Drew et al 2003; Greenhorn et al. 2018). There are several reasons for these reintroductions, but all are correlated with extirpated or severely reduced fisher populations. Lewis et al. (2012) found motivation for North American 
fisher reintroductions fell into several categories: reestablish native fauna (63\%), control porcupine (37\%), establish a furbearer population (16\%), initiate research (5\%) or a combination of these $(26 \%)$.

Although West Virginia genetic data are significantly lacking, there are numerous studies on fisher and related mustelid genetics across North America. Studies have primarily focused on genetics of fisher populations in the Great Lakes regions of Canada (Hapeman et al. 2017; Stewart et al. 2017; Greenhorn et al. 2018; Bertrand et al. 2017; Garroway et al. 2008). Other studies have focused on the genetics of western populations of fisher (Tucker et al. 2012; Tucker et al. 2017) as well as midwestern populations (Williams et al. 2000). Using genetic analysis, Stewart et al. (2017) found that in some areas of Canada, individuals reintroduced in Ontario and Manitoba did not expand into the nearby native fisher population (Cooking Lake Moraine population). Rather it appeared that the Cooking Lake Moraine population expanded due to natural recolonization, without significant gene flow from the reintroduced population. This study points out the importance of genetic analysis in revealing cryptic recolonization, which otherwise may have been interpreted as reintroduction success. One study found that reintroduced fisher populations in the Great Lakes region have led to genetically distinct populations with rapid recovery following bottlenecks in these fisher populations, and that individuals are capable of long-distance dispersal as evidenced through landscape genetic analysis (Hapeman et al. 2017). In the western United States, a reintroduced Sierra Nevada population was found to have a moderate amount of genetic diversity and genetic isolation by distance was observed in this population (Tucker et al. 2013). Additionally, fisher movement data was compared with genetic diversity to develop sex-specific graphs to determine gene flow 
and migration distance, with results indicating that snow depth had a negative effect on female fisher dispersal (Bertrand et al. 2017).

\section{Genetic Monitoring of Reintroduced Populations}

Most modern reintroductions of wildlife include genetic monitoring. This is important in choosing which individuals will be translocated and considered the founders of the new population. Often the goal is to select individuals that will not jeopardize the genetic or conservation goals of the reintroduction (Russel et al. 1994). When effectively small numbers of individuals are selected as the founders, genetic diversity can be lost (Sasmal et al. 2012). The more individuals translocated, the higher the chance of rare alleles contributing to the founder population, which in turn promotes genetic diversity. When possible, a widespread study should be conducted on all possible source populations for a reintroduction. These studies should examine genetic diversity within and among the candidate source populations, such as conducted with northern leopard frogs in western Canada (Wilson et al. 2008). Techniques used included linear regressions between genetic diversity and longitude of the frog by evaluating allelic richness, expected heterozygosity and haplotype numbers to determine geographic areas as potential source populations. The common goal across reintroductions is to maintain long-term genetic diversity, through a single translocation at one time or several translocations over time (Muller et al. 2018). Once reintroduced populations are established, managers need to conduct genetic monitoring to track gene flow and admixture in restored populations. Since reintroduced populations are at higher risk to being bottlenecked, they are of substantial conservation concern as these founding populations are subject to stochastic genetic changes which can reduce their viability (Ewing et al. 2007). 
The best way to control genetic diversity in a reintroduction is with captive breeding and deliberate selection of released individuals based on individual genetic structure. This method allows all parentage to be known, so that managers can "build" genetic variation in their population such that it may persist independently as a wild population. The case of the blackfooted ferret is one of the best-known North American captive breeding programs to restore a nearly extinct species to part of their historic range. This program's genetic goal was to retain $90 \%$ of the original heterozygosity for 50 years through on-going captive breeding and releases (Russel et al. 1994). Overall, most reintroductions utilize genetic monitoring to analyze these three components: 1) differences of genetic diversity in captive, reintroduced and supplemented populations for management decisions, 2) levels of admixture following the release of individuals of different breeding lines, and 3) temporal changes in population size and genetic diversity (LaHaye et al. 2017).

\section{Thesis Objectives}

To genetically assess the West Virginia fisher population, this thesis will include three additional chapters: Contemporary Population Structure: Reintroduction, Recolonization, or Resurgence (Chapter 2), Maximizing Genetic Diversity of Reintroduction Events (Chapter 3) and Management Implications (Chapter 4). Chapter 2 will evaluate the population genetic structure of fisher in West Virginia, Pennsylvania, New Hampshire, and New York. Chapter 3 will assess the genetic diversity captured in contemporary fisher samples taken from West Virginia, Pennsylvania, New York and the source population, New Hampshire. This chapter will highlight any significant differences between West Virginia and New Hampshire, focusing on an importance of comparing the source and reintroduced populations. All four states will be compared to support contemporary genetics of historic reintroductions to West Virginia and 
Pennsylvania. Chapter 4 will discuss what these results mean for local managers of this fisher population and the future of management.

Contemporary populations of fisher in West Virginia could have any combination of three potential sources, the first being that the contemporary population was fully founded by the 23 individuals translocated from New Hampshire. The second is that recolonization occurred from bordering Pennsylvania and Maryland populations; however, these states attribute their contemporary populations to the West Virginia release of 23 individuals (personal communication, Rich Rogers, WVDNR). Lastly, there is a possibility of unknown remnant individuals in West Virginia, which experienced a resurgence immediately following the release of 23 individuals. I hypothesize there will be contemporary population structure that reflects historic reintroductions, specifically evidence of New Hampshire structure found in West Virginia. Additionally, I hypothesize that historic reintroductions may be visible through structure across all four states in this study. I predict the majority of gene flow within West Virginia will occur with the Pennsylvania border, and will extend into the southwestern and south-central areas of Pennsylvania. I predict that any structuring of New Hampshire and West Virginia samples will be a result of the historic translocation of fisher between these areas. I also predict that genetic diversity will be lower in West Virginia compared to the source population (New Hampshire) due to the relatively small number of founders during reintroduction.

In this study, I will measure population genetic structure and genetic diversity of fishers trapped within West Virginia and nearby states to provide a more thorough interpretation of the population ecology of the species. Results will help guide fisher management and future conservation efforts. In order to achieve this goal, my objectives are to: 
Objective 1: Assess the contemporary population structure of the West Virginia fisher population

1. Determine if population structure is present in fisher in West Virginia

2. Identify whether gene flow is occurring between West Virginia and neighboring states

Objective 2: Evaluate reintroduction success of the fisher population in West Virginia

1. Compare genetic diversity in West Virginia to the source population and neighboring states

2. Compare the effective population size of the West Virginia population to the source population and neighboring state 


\section{Chapter 2: Contemporary Population Structure: Reintroduction, Recolonization, or Resurgence?}

\section{Introduction}

Cryptic recolonization, resurgence, and founder's effect are all cause for significant genetic analysis before, during, and after reintroduction events. While a single genetic assessment can be a snapshot of population genetics, there is less insight of dynamic processes to population structure after reintroduction, such as gene flow, changes in differentiation among populations, and allele frequency changes within populations (Schwartz et al. 2007). Unfortunately, the West Virginia fisher population received very little to no attention of genetic analysis before or during the reintroduction event (Williams et al. 1999, Williams et al. 2000). This study is the first comprehensive population structure analysis of the West Virginia fisher population after significant establishment following reintroduction.

Stewart et al. (2017) stated that after an intended reintroduction event, there were three likely hypotheses about the status of their reintroduced fisher population: 1) a successful reintroduction occurred with one or more source populations present in contemporary samples, 2) inadvertent reinforcement, in which a previously undetected population was occupying the area prior to reintroduction, indicated by unique alleles, or 3) natural recolonization, where the contemporary fisher individuals are most related to adjacent fisher populations, without evidence of their source populations. To evaluate the status of wild populations as non-invasively as possible, population structure can be assessed using genetic data. With the analysis of genetic structure, information on substructure, gene flow among subpopulations, and isolation from neighboring populations can be quantified (Dalen et al. 2006). Since the inclusion of genetic data in wildlife management, agencies are expected to justify regulations based on contemporary 
population structure (Reding et al. 2013). Understanding which individuals represent separate and unique populations, as well as geographic barriers between populations, gives wildlife managers a better idea of how to effectively manage these populations. This may be especially important with cryptic, solitary species such as fisher (Pekania pennanti).

While countless studies aim to determine the success of reintroduction event(s), there is no standard for comparison or discrimination of a successful reintroduction based on translocated founders from underlying recolonization from adjacent populations or resurgence of relict populations (Robert et al. 2015; Stewart et al. 2017). This can arise when biologists overestimate reintroduction success while concurrently underestimating the recolonization success of a species, especially one thought to be extant before the reintroduction event(s). One study revealed the resurgence of a remnant population of fisher after reintroduction events in an area where all evidence indicated the fisher was locally extirpated for at least 50 years (Stewart et al. 2017). In West Virginia, fisher were considered extirpated by the 1920's until reintroduction in 1969 (Lesser and Cromer 2015).

Traditionally, a reintroduction-based population is expected to reveal one or all source populations present within contemporary genetic sampling (Williams et al 2000, Stewart et al. 2017). As more genetic assessments following reintroductions are conducted in the wildlife conservation community, there is evidence to support that recolonization can bolster reintroduction success (Stewart et al. 2017). While many ecological, social and demographic factors can influence these populations, recolonization is a mechanism that can result in rapid changes in population genetic structure (Greenhorn et al. 2018). Several reintroduction studies have seen this cryptic recolonization, such as with Alpine marmot (Marmota marmota). Kruckenhauser and Pinsker (2004) reviewed three contemporary reintroduced marmot 
populations and discovered they were more closely related to neighboring populations than putative founders from France. Another study found much higher dispersal in elk (Cervus elephus) than previously thought due to very high genetic diversity within and very low genetic divergence between reintroduced populations (Hicks et al. 2007).

Secondarily, the divergence from expected source population diversity and structure in contemporary reintroduced populations can be a result of founder's effect. The founder's effect, following a founder event, has empirically been studied following introductions of species to new or historic ranges. Studies have indicated that founder events typically reduce allelic diversity, and in rare events, heterozygosity (Baker \& Moeed 1987; Tarr et al. 1998; Friar et al. 2000; Clegg et al. 2002; Hufbauer et al. 2004; Pruett \& Winker 2005). Founder's effect is studied with introductions, since the translocation of animals typically is a small sample of individuals that are meant to start the colonization process in an area. The fisher reintroduction of West Virginia included 23 individuals as founders. This follows the theory that due to founder events, genetic structure and lowered diversity is expected on the expansion front at the early stages of recolonization (Excoffier et al. 2009). Then, as expansion continues, there is a restoration of connectivity typically leading to genetic homogenization and increased diversity (Excoffier et al. 2009). Similar to recolonization, founder events may be associated with rapid changes in population structure (Hawley et al 2005).

Population resurgence is difficult to pinpoint and is often attributed simply as natural recolonization from adjacent populations (Stewart et al. 2017). Resurgence implies there are cryptic individuals persisting unknown to managers and often follows an event of extreme contraction and subsequent rapid expansion, like we see in fisher populations across North America (Doerner et al. 2005, Lewis et al. 2012). The evidence for this can be seen in private 
alleles relative to adjacent populations. A resurgence of a population has genetic consequences similar to that of a bottleneck or founder's effect (Doerner et al. 2005, Hawley et al. 2005, Knapp and Connors 1999). Characteristics of a recent bottleneck and founder's effect include significant reductions in the ratio of number of alleles to range of allele size within populations, resulting in low genetic diversity (Knapp and Connors 1999, Hawley et al. 2005). Thus, evidence of private alleles relative to adjacent populations in a population showing evidence of a bottleneck or founder's effect might suggest the resurgence of cryptic individuals. This is typical of re-establishing fisher populations, though commonly attributed as natural recolonization of adjacent populations (Stewart et al. 2017, Lewis et al. 2012, Hapeman et al. 2011). These studies considered fisher extirpated when no more reports of fisher sightings or harvest occurred following the 1900's, when most populations experienced significant constrictions of their total range (Lewis et al. 2012).

\section{Fisher in North America}

After natural recolonization and reintroductions, fisher have been able to recover in parts of their historic range, such as eastern North America and Montana; however, many populations remain absent or fragmented in the Pacific northwest and south of the Great Lakes (Williams et al. 2006). Although West Virginia population genetic structure data are significantly lacking, there are numerous studies on fisher and related mustelid genetics across North America. Studies have primarily focused on genetics of fisher populations in the Great Lakes regions of Canada (Hapeman et al. 2017; Stewart et al. 2017; Greenhorn et al. 2018; Bertrand et al. 2017; Garroway et al. 2008). Other studies have focused on the genetics of western populations of fisher (Tucker et al. 2012; Tucker et al. 2017) as well as midwestern populations (Williams et al. 2000). Using genetic analysis, Stewart et al. (2017) found that in some areas of Canada, individuals 
reintroduced in Ontario and Manitoba did not expand into the native nearby fisher population (Cooking Lake Moraine population). Rather it appeared that the Cooking Lake Moraine population expanded due to natural recolonization, without significant gene flow from the reintroduced population. This study points out the importance of genetic analysis in revealing natural recolonization, which otherwise may have been interpreted as reintroduction success. Hapeman et al. (2017) found that reintroduced fisher populations in the Great Lakes region have led to genetically distinct populations with rapid recovery following bottlenecks in these fisher populations, and that individuals are capable of long-distance dispersal as evidenced through landscape genetic analysis. In the western United States, Tucker et al. (2013) found the reintroduced Sierra Nevada population to have a moderate amount of genetic diversity and found genetic isolation by distance in this population. Wisely et al. (2004) found two distinct populations of fisher in southwestern Oregon. West coast fisher exist as two remnant populations (Northern California and southern Sierra Nevada) and three reintroduced populations (western Washington, southern Oregon and northeastern California) (Sweitzer et al. 2015). These five populations have been managed as the West Coast Distinct Population Segment (DPS) by the U.S. Fish and Wildlife Service since October 2015.

\section{Fisher in West Virginia}

The West Virginia Division of Natural Resources (WVDNR) reports that the fisher population has slowly grown since the translocation of 23 individuals from New Hampshire to West Virginia in 1969. Today, the WVDNR predicts there are 1000-2000 individuals in the forested areas of West Virginia (personal communication, Rich Rogers, WVDNR). While reports of fisher sightings have occurred throughout the state since the release, harvest reports indicate densities are highest along the northern Allegheny Mountain and eastern panhandle ridge and 
valley counties, and along the Pennsylvania and Maryland borders (Figure 1). Today's fisher population in West Virginia is thought to be directly sourced from the New Hampshire population, with possible natural recolonization occurring via bidirectional migration from neighboring states (MD, PA, VA), specifically migration between a reintroduced/translocated Pennsylvania population that received their individuals from both New Hampshire and New York in 1979 and 1994-1998 (Lewis et al 2012).

This West Virginia population has previously been evaluated to determine reintroduction success (Stewart et al 2017; Williams et al. 2000, Williams et al. 1999). Williams et al. (1999) state that the New Hampshire source population had an "ambiguous" (a term used in their study that the strength of relatedness could not be confirmed) contribution of reintroduced individuals to the contemporary West Virginia genetic population. Stewart et al.'s (2017) review of the New Hampshire and West Virginia reintroduction also concluded the reintroduced population was "ambiguous" but of 20 fisher reintroductions across North America, $47 \%$ had been given a new reintroduction status after genetic testing for reintroduction success. This typically meant a population that appeared reestablished did not have significant contemporary representation of the source population. The limited genetic data available on the West Virginia fisher population highlights the need for continuous genetic assessment post-reintroduction of fisher in any location.

\section{History of Fisher in Surrounding States}

Pennsylvania's modern fisher population was established after 30 fisher were translocated from the Adirondack Mountains in New York in 1979 as well as natural colonization from the 1969 reintroduction in West Virginia (Larkin et al. 2010). Additionally, Pennsylvania regenerated 6.5 million ha of forest, providing good habitat for the fisher. The state conducted a reintroduction of 
their own during 1994-1998, translocating 190 fisher from New York and New Hampshire source populations (Larkin et al. 2011). Today’s Pennsylvania populations are considered established in central, northern and southwestern areas of the state with a record 503 fisher harvested during the 2015-2016 trapping season (PGA 2016, Williams et al. 2000). Genetic studies have been conducted on the Pennsylvania fisher population, revealing fisher from West Virginia expanding to southcentral and southwestern Pennsylvania (Larkin et al. 2011, Ellington 2010). This was a result of 359 Pennsylvania fisher samples tested from 2006-2014, which laid out geographically the presence of two populations ("north" (New York sourced genetics) and "south" (West Virginia sourced genetics)) across the state of Pennsylvania. Both New York and West Virginia fisher samples were included in that study to determine the "north" and "south" genetics. There is evidence of admixture of these "north" and "south" populations where they meet in central Pennsylvania. Historic genetic data of the state's population collected during 2011-2015 found admixture between Pennsylvania and West Virginia populations near the south and admixture between Pennsylvania and New York in the north east of the state. However, these results for West Virginia were based on a small sample size $(n=9)$.

While New Hampshire's fisher population has fluctuated since the $19^{\text {th }}$ century, this population has provided numerous individuals for reintroductions or augmentations in other states since the mid-twentieth century. Similar to the rest of North America, New Hampshire's fisher population was near extinction due to unregulated trapping and habitat loss. In recent years, trapper harvest reports indicate the population may be increasing. While many studies relate to New Hampshire as a source population and compare relative diversity of NH fisher to their reintroduced counterparts (Williams et al. 2000, Lewis et al. 2012), population structure within the state has not been widely researched. Similar to New Hampshire, New York's 
population has fluctuated throughout the centuries. Their population was restricted to only the Adirondacks by the mid 1930's. New York protected their remaining fisher with limited harvest since 1937 (Saunders 1988). Fisher from the Adirondacks were translocated to the Catskills of New York in the 1970's (Stuhmiller 2010). There are approximately 3000-4000 fisher inhabiting Adirondack Park in New York. Again, there are not clear data about population structure within the state.

\section{Objectives}

The objectives of this chapter are to assess population genetic structure of the West Virginia fisher population and compare it to PA, NY and NH populations. I intend to provide evidence of what the contemporary population structure is for this reintroduced fisher population since the release of 23 individuals to the state in 1969, following assumed long-term (>50 years) extirpation from the state.

\section{Methods}

\section{Data Collection}

Sample collection relied primarily on West Virginia trapper harvests of fisher. News releases and contacting successful trappers during the 2018-2019 and 2019-2020 West Virginia trapping seasons provided trapping and hunting harvest samples. Participating trappers provided samples by 1) returning a sample kit or 2) contacting a local WVDNR biologist for in-person sample delivery. The sample kits included a questionnaire about how and where the fisher was caught, 2-ml test tubes with $95 \%$ ethanol for muscle or organ samples, and coin envelopes for tanned skin or fur samples $(n=87)$. I also reached out to several states with fisher populations that likely had gene flow with the West Virginia population or the source population used for translocation. We included samples from Pennsylvania $(n=340)$, New York $(n=22)$ and the 
source for West Virginia's fisher population: New Hampshire $(\mathrm{n}=13)$. All muscle and organ (typically tongue, skeletal muscle and liver) were stored in $95 \%$ ethanol once collected from the trapper. All tanned skin and hair samples were stored in coin envelopes. Any tissue sample received without ethanol or in a compromised state was immediately stored in the freezer to stop decomposition. All PA samples were processed and genotyped from 2011-2015 at the Rocky Mountain Research Station, Missoula, MT (Larkin et al. 2011). I received 16 DNA samples (along with their genotypes) from this study for local standardization with our lab equipment and protocols to ensure allele designations were the same as our in-house samples.

\section{DNA Extraction and Amplification}

I extracted DNA from tissue samples using the QIAGEN DNeasy Blood \& Tissue kit and protocol (Hilden, Germany). Tanned skin and hair samples followed the QIAGEN DNeasy Blood \& Tissue protocol modified by Rounsville (2018) to include $20 \mu \mathrm{l}$ of DTT during cell lysis and 3-6 hours of vacuum evaporation to increase DNA concentration due to the often-poor quality and quantity of DNA in hair/tanned skin samples (Ojeda et al. 2011). Muscle, organ and skin tissue samples were cut to $\sim 3 \mathrm{~mm}^{2}$ and hair samples consisted of 3-10 hairs with root attached, cut off at $\sim 2 \mathrm{~cm}$ to ensure they did not extend past the sample tube (Stewart et al. 2012; Ojeda et al. 2011). All DNA samples were quantified and diluted to a concentration of $10 \mathrm{ng} / \mu \mathrm{l}$ using a ThermoFisher NanoDrop Lite spectrophotometer. PCR amplification was conducted at nine microsatellite loci previously used by Dr. Jeff Larkin at Indiana University-Pennsylvania. The primers we used for these 9 loci were developed by Davis and Strobeck (1998; Mal in American marten), Duffey et al. (1998; Ggu101 in wolverine), Turner et al. (1998; Tt1 in badgers), Abadia-Cardoso et al. (2017; Pv9 in grey seals), and Jordan et al. (2007; MP144, MP175, MP197, MP200 and MP247 in fisher). These microsatellite loci were amplified using 
two multiplex reactions: A (MP144, Pv9, MP197, Ggu101, and MP247) and B (Tt1, MP200, and MP175). The total reaction volume for each multiplex was $10 \mu \mathrm{l}$ and contained $5 \mu \mathrm{l}$ of $2 \mathrm{X}$ Qiagen Multiplexing Master Mix (Germantown, MD), $100 \mathrm{nmol}$ of each primer mix A and B, and 20 ng of DNA template. Polymerase-chain reaction (PCR) protocols varied between robust tissue samples and weak hair/tanned skin samples. For high quality tissue samples, PCR was run at 1) $95^{\circ} \mathrm{C}$ for $15: 00 \mathrm{~min}$, 2) $94^{\circ} \mathrm{C}$ for $0: 30 \mathrm{sec}$, 3) $57^{\circ} \mathrm{C}$ for $\left.1: 30 \mathrm{~min}, 4\right) 72^{\circ} \mathrm{C}$ for $1: 00 \mathrm{~min}, 5$ ) repeat steps $2-429 \mathrm{x}, 6) 60^{\circ} \mathrm{C}$ for $30: 00 \mathrm{~min}$, and 7) hold at $12^{\circ} \mathrm{C}$. Low quality hair samples were run on a modified version of this PCR: 1) $95^{\circ} \mathrm{C}$ for $15: 00 \mathrm{~min}, 2$ ) $94^{\circ} \mathrm{C}$ for $0: 30 \mathrm{sec}$, 3) $55^{\circ} \mathrm{C}$ for 1:30 min, 4) $72^{\circ} \mathrm{C}$ for $\left.1: 00 \mathrm{~min}, 5\right)$ repeat steps $2-444 \mathrm{x}$, 6) $68^{\circ} \mathrm{C}$ for $30: 00$ min, and 7) hold at $12^{\circ} \mathrm{C}$. Any samples that produced weak ( $<5$ loci amplified) or no amplification were reanalyzed or omitted from the study. The assembled genotypes were screened by MICRO-CHECKER (Van Oosterhout et al. 2004) to address and remove any genotyping errors.

\section{Population Genetic Structure Analysis}

Fisher samples were given location assignments by which state the individual was harvested or found. However, structure-based population assignment was conducted to determine the most likely number of genetically distinct populations across all samples. A Bayesian analysis using the program STRUCTURE (Pritchard et al. 2000, Falush et al. 2003, Falush et al. 2007) was used to uncover the level of genetic population structure throughout this central-eastern region of fisher in North America. We conducted 5 iterations testing a range of possible population clusters $(K=[1,7])$ with a 1,000 repetition burnin followed by 10,000 Markov Chain Monte Carlo (MCMC) for the admixture model at each level of $K$ assumed populations or genetic groups. Outputs from this model were then analyzed by STRUCTURE Harvester (Earl and vonHoldt 2012) to determine the most likely K, or number of distinct populations. The most 
likely $\mathrm{K}$ value was determined by identifying the $\mathrm{K}$ value with the highest likelihood and least variability among iterations and by the highest $\Delta \mathrm{K}$ (Evanno et al. 2005). This analysis was applied to all samples to examine regional population structure and to just West Virginia samples to determine any within-state structure. Additionally, 35 West Virginia samples were separated by sex and assessed as male $(n=21)$ and female $(n=14)$ groups, as well as 331 Pennsylvania samples assessed as male $(\mathrm{n}=160)$ and female $(\mathrm{n}=171)$ groups. Percentage analysis of each individual combined with their location data was used to create a map of population percentage by location per sample in ArcGIS Pro. Samples were given population A (red), B (green), or C (blue) based on the highest population percentage of the three possible populations across all four states. An admixture map was created for populations assigning at $<0.8$ and the top two populations were combined to represent admixture as $\mathrm{AB}$ (orange), $\mathrm{BC}$ (green), $\mathrm{AC}$ (purple) as well as samples assigning $>0.8$ as A (red), B (yellow), and C (blue). A second map was created to represent population percentage per sample of only West Virginia samples. Private alleles in the West Virginia population were identified through program GenAlEx v.6.503 (Peakall and Smouse 2012).

Population structure was also assessed through a principal coordinates analysis (PCoA). I used program GenAlEx v.6.503 (Peakall and Smouse 2012) to conduct a PCoA by first calculating a Nei's pairwise genetic distance matrix across all loci (Nei 1972). These genetic distances were used to create a PCoA of all samples and another PCoA of just West Virginia samples.

The next analysis was measuring the level of genetic differentiation between the different states $\left(\mathrm{F}_{\mathrm{ST}}\right.$ ), using the software FSTAT v.2.9.3 (Goudet 1995). Significance was assessed at $\alpha=$ 0.05. The $\mathrm{F}_{\mathrm{ST}}$ value is the genetic variance of the subpopulations (different groups in the states) 
in relation to the total genetic variation (all populations together). High $\mathrm{F}_{\mathrm{ST}}$ values indicate a high degree of genetic differentiation between populations.

\section{Results}

The STRUCTURE analysis revealed three populations $(\mathrm{K}=3)$ across all populations and three populations ( $K=3$ ) within West Virginia (Figure 2). Across the region, there appears to be three distinct populations (green, blue, and red; Figure 3A) with the "blue" population being dominant in the WV samples. Within Pennsylvania, there is a high level of admixture between red and green, with a small "red" pocket and about 1/3 of the PA samples assigning to the "green" population. In the NY samples, there is an even mix of "red" and "blue" populations and in NH the "red" cluster is dominant (Figure 3A). When these population clusters are mapped,

different geographical pockets of admixture are revealed (Figure 4, Figure 5, Figure 6). While all three population clusters are found in each state, there is a clear pattern of source populations (NY and NH) represented heavily in both WV and PA as "red" and "blue" populations. Both West Virginia and New Hampshire share the "red" population as their highest percentage. West Virginia is represented by $49 \%$ "red", $30 \%$ "green" and $21 \%$ "blue" populations (Figure 4). In New Hampshire, $62 \%$ is "red", $23 \%$ is "green" and only $15 \%$ is "blue" (Figure 4). There is a frequent occurrence $(61 \%)$ of the "green" population in Pennsylvania (Figure 4). The PCoA analysis across all four states did not reveal three clusters as expected from the STRUCTURE result, but rather a drifting secondary cluster from a tight main cluster represented primarily by Pennsylvania fisher (Figure 7A).

Individuals with a proportion of membership $<0.8$ to a population were considered admixed and were identified by the two populations with the highest proportion of membership 
( $\mathrm{AB}, \mathrm{BC}, \mathrm{AC}$ ). West Virginia's highest percent after incorporating admixture is $\mathrm{C}=47.6 \%$ followed by $\mathrm{A}=23.8 \%$, and the lowest is $\mathrm{BC}=2.4 \%$ followed by $\mathrm{AB}=3.6 \%$. Pennsylvania's highest percent after admixture is $\mathrm{B}=47.5 \%$ followed by $\mathrm{A}=31.2 \%$ and the lowest is $\mathrm{C}=0.6 \%$ followed by $\mathrm{AC}=2.4 \%$ and $\mathrm{BC}=3.3 \%$. New York's highest percent after admixture is $\mathrm{A}=$ $36.4 \%$ followed by $\mathrm{C}=27.3 \%$, and the lowest is B and AC both at $4.5 \%$. New Hampshire's highest percent after admixture is $\mathrm{A}=53.8 \%$, followed by $\mathrm{B}=23.1 \%$ and both $\mathrm{AB}$ and $\mathrm{C}$ are at $0 \%$ (Table 1, Figure 6).

West Virginia appears to have three distinct populations $(\mathrm{K}=3)$ with no apparent correlation to geographical barriers (Figure 3B, Figure 7). The PCoA analyses also support substructure within West Virginia, producing 3 clusters within the state (Figure 7B). West Virginia has 5 private alleles across 9 loci when compared to all states (MP144-172, MP197209,-219, MP247-145, MA1-210). When West Virginia's 35 samples were separated by sex, the PCoA did not result in a clear clustering by sex. Pennsylvania's 331 samples with sex information also did not cluster by sex based on PCoA (Figure 8).

The highest FST value (i.e., highest genetic differentiation) between state populations is New York-Pennsylvania $\left(\mathrm{F}_{\mathrm{ST}}=0.065\right)$, closely followed by New York-West Virginia $\left(\mathrm{F}_{\mathrm{ST}}=\right.$ 0.063; Table 2). The lowest genetic differentiation is between New York-New Hampshire ( $\mathrm{F}_{\mathrm{ST}}=$ 0.012, Table 2). All pairwise FST comparisons were significant $(\mathrm{P}<0.05)$ except between New York and New Hampshire $(\mathrm{p}=0.142)$. The pairwise $\mathrm{F}_{\mathrm{ST}}$ comparison between West Virginia and New Hampshire was significant $\left(\mathrm{F}_{\mathrm{ST}}=0.0345\right.$, $\mathrm{p}$-value $=0.00833$, alpha $=0.05$; Table 2). Males and females were not genetically distinct from each other in West Virginia $\left(\mathrm{F}_{\mathrm{ST}}=0.003, \mathrm{p}=0.15\right)$ or Pennsylvania $\left(\mathrm{F}_{\mathrm{ST}}=-0.001, \mathrm{p}=0.70\right)$. 


\section{Discussion}

\section{West Virginia Population Structure}

To recap, Stewart et al. (2017) stated that after an intended reintroduction event, there were three likely hypotheses about the status of their reintroduced fisher population: 1) a successful reintroduction occurred with one or more source populations present in contemporary samples, 2) inadvertent reinforcement, in which a previously undetected population was occupying the area prior to reintroduction, indicated by unique alleles, or 3) natural recolonization, where the contemporary fisher individuals are most related to adjacent fisher populations, without evidence of their source populations. To address the first hypothesis, the single reintroduction to West Virginia was supported by our population structure results since West Virginia and New Hampshire share the same highest population of "red" at $49 \%$ and $61 \%$, respectively. Therefore, it is likely that today's population reflects a successful reintroduction from New Hampshire.

West Virginia's fisher population has significant substructure, revealing three populations within the state. The recent reintroductions in West Virginia (1969: 23 founders) and neighboring state Pennsylvania (1979: 30 founders, 1994-1998: 30 founders) are the recorded contributors to the modern metapopulation of fisher in West Virginia, again supporting successful reintroductions. However, it is possible that the smaller reintroduction sizes may have produced genetic differences due to the founder's effect (Excoffier et al. 2009). This result of founder's effect potentially occurred in each relocation event within West Virginia and Pennsylvania from 1969 to 1998 . These small founding populations may have contained highly related individuals or very low allelic diversity due to sampling error. Thus, this could create contemporary pockets of highly similar populations among other well-dispersing populations. Populations may not be old enough to overcome the initial reduction of genetic diversity during 
translocation, and some populations do not overcome their initially low diversity at all (Habel and Zachos 2013). The substructure observed in West Virginia is also supported by the PCoA revealing 3 clusters (Figure 7.A). The areas of tight clustering represent relatively close genetic distances between individuals, possible evidence of founder's effect creating one or more of these genetic "pockets" (Bray et al. 2010).

The second hypothesis presented by Stewart et al. (2017) of inadvertent reinforcement, or a resurgence, of undetected individuals following a reintroduction is also supported since there are 5 private alleles in the West Virginia population. This could be evidence of individuals remaining (containing these 5 alleles) undetected in West Virginia, which the released individuals bred with creating gene flow and quickly reestablishing the population.

According to the Allee effect, low reproductive rates tend to be correlated with low population densities since it is harder to find mates. This may have influenced the initial release of fisher to the state. The reintroduction of 23 individuals may have provided the necessary boost in density to get past the Allee effect. Early reports following the 1969 reintroduction found that the release of 15 individuals to Tucker, Co. led to significant expansion into the Monongahela National Forest whereas there was no expansion from the 8 individuals released in Pocahontas Co (Cromer 2002). It is possible there were no cryptic, undetected individuals in Pocahontas Co. and thus no expansion without support of gene flow and connectivity, or that 8 released individuals were not enough to overcome the Allee effect. However, it is very likely there were cryptic, undetected individuals in Tucker Co., as well as the larger release number $(\mathrm{n}=15)$ providing the connectivity needed for significant expansion following the release. Also, geographic mapping of the identified clusters in West Virginia does not reveal strong geographical clustering (Figure 4, Figure 5, Figure 6). This supports evidence of remnant 
populations or founder's effect from reintroductions present as contemporary population divides across the sampled areas, without geographic clustering.

The last hypothesis of natural recolonization, where contemporary fisher individuals are most related to adjacent fisher populations with limited evidence of their source populations, is not strongly supported by my results. While natural recolonization may have occurred at a low level with Pennsylvania and Maryland, it is more likely that the resurgence of fisher in the Monongalia National Forest led to natural recolonization to these states, rather than from them. This is supported by Maryland and southern Pennsylvania agencies attributing their contemporary fisher populations to the 1969 West Virginia reintroduction, since expansion in these areas was seen only after the reintroduction (personal communication, Rich Rogers, WVDNR).

It is clear the representation of WV fisher does not encompass the entire state. Since the first trapping season was opened for fisher in 1972, three years post release, the pattern of fisher presence has remained the same (Figure 1, Figure 4). Wildlife biologists in West Virginia agree that there is suitable habitat in other areas of the state, but without cryptic, remnant individuals in these areas, the reintroduction was unable to support re-establishment such as in the Pocahontas Co. release. The locations of samples tested in West Virginia correlate with the historic harvest map, limited to north-central areas of West Virginia (Figure 1, Figure 4). It is possible there are remnant fisher in other parts of West Virginia but trapping effort has yet to reveal this. Based on direct and indirect communication with West Virginia trappers, although highly prized, trappers do not spend a lot of time pursuing fishers. Most fisher trapped in West Virginia are incidental or nontarget catches in sets originally intended for fox or coyote. Direct effort to survey fisher 
populations in other parts of the state may reveal additional distinct populations or a new source of gene flow.

\section{All States Population Structure}

Across West Virginia, Pennsylvania, New York and New Hampshire, there is significant population structure, with 3 populations identified. This structure can also be attributed to the previously mentioned historic reintroductions and likely represents founder's effects from these reintroductions. While we can see that historic introductions across mid-Atlantic fisher range have remained viable, the presence of multiple populations at a single location and substantial levels of admixture could also indicate resurgence of remnant individuals (Stewart et al. 2017, Carr et al.2007). Evidence of fisher reintroduction success attributed to recolonization of adjacent established populations, especially when local populations were considered extinct, has been seen in North American fisher (Stewart et al 2017, Carr et al. 2007). For example, genetic assessment of Algonquin Park reintroduced fisher populations found evidence of recolonization from multiple sources, meaning multiple remnant populations survived the extirpation event of the 1950's in this area or natural recolonization occurred from multiple neighboring populations (Carr et al. 2007). However, despite this trend in other reintroduced fisher populations, it appears our West Virginia population was reestablished primarily by historic reintroductions with a resurgence of remnant individuals driving gene flow and connectivity to neighboring states. One would suspect if natural recolonization (established populations moving into the reintroduced population) was playing a large role in the re-establishment of fisher in West Virginia, established range would be larger throughout the state (south and southwestern regions; Figure 
1). Since this is not seen in the state, again I must conclude that the reintroduction event itself led to re-establishment, aided by cryptic, remnant individuals near the Tucker Co. release site.

A visual confirmation of founder's effect and reintroduction history across all four states is the lack of strong geographic association to the genetic populations present in our total study area (Figure 4). While the smaller reintroduction events $(n=23, n=30)$ may have contributed to contemporary founder's effect, there was also a very large event of 190 founding individuals translocated to Pennsylvania. It is possible the large "green" population that is relatively ubiquitous over the Pennsylvania range (Figure 4) is a result of this large reintroduction event. This "green" population is the only indication of possible geographic distinction, since it mostly persists in Pennsylvania; however, the "green" population can be found at minimal levels in all other states sampled, indicating likely gene flow. This could be evidence of high habitat suitability for fisher in Pennsylvania.

The clustering pattern of the PCoA across all states is not quite indicative of the 3population substructure that STRUCTURE supports, but it may reveal a more complex level of structure (Figure 7B). Pennsylvania clusters very tightly with itself, while West Virginia, New York and New Hampshire follow a broad band together. Again, this could be a result of that large reintroduction event in Pennsylvania and high habitat suitability in the state. The tight clustering of Pennsylvania could also be the result of the large sample size $(n=340)$. It should be noted that separating West Virginia and Pennsylvania's populations by sex did not indicate sexbiased dispersal.

\section{Conclusion}

Based on numerous previous fisher studies and general wildlife reintroduction assessments, West Virginia's fisher population has successfully established since translocation, likely driven by 
successful reintroductions and the resurgence of cryptic, remnant populations. The breadth of 3 distinct populations spread across four states is likely a result of founder events following reintroductions. There could have also been remnant individuals/populations of fisher supporting contemporary gene flow and connectivity within populations. Through these results, I have uncovered an eastern-central metapopulation, shaped by historic translocation events that provided founding genetic diversity to three contemporary population groups. 


\section{Chapter 3 Maximizing Genetic Diversity of Reintroduction Events}

\section{Introduction}

Assessments of genetic diversity are the "snapshot" of genetic conservation status of an individual or population. Studies that measure genetic diversity typically assess observed and expected heterozygosity, allele number, number of effective alleles, and inbreeding coefficient (Gallardo-Alvarez et al. 2019). The importance of heterozygosity is the potential for immediate adaptive response by maintaining or increasing observed heterozygosity of a population (Neel and Cummings. 2003). These "snapshots" can be key in determining the success or progress of a reintroduction project. When populations are small, they become susceptible to extinction via demographic stochasticity, inbreeding and environmental fluctuations (Komers and Curman 2000). We know that populations tend to lose diversity if a small number of individuals are used as founders for reintroductions. These small populations, due to random events (e.g., die-offs) or sampling error (very few individuals translocated), can also lead to founder's effect resulting in low allelic diversity. This is a concern for the founding individuals translocated for reintroduction events which typically start as a small population (Nei et al. 1975). In West Virginia, the fisher reintroduction consisted of one event of 23 individuals released in two West Virginia locations (Pocahontas Co. and Tucker Co.). Therefore, this chapter aims to measure the success of West Virginia's fisher reintroduction in 1969 of 23 individuals to the approximate 1000-2000 individuals in the state today using current genetic data and diversity assessments (personal communication, Rich Rogers, WVDNR).

Based on numerous reintroduction studies, there are typical variables of reintroductions assessed to deem if the reintroduction is successful. The first and most typical is that a translocation or reintroduction event is a success if it results in a self-sustaining population 
(Griffith et al 1989). A key to population growth towards a self-sustaining population is a large initial founding population. In general, many founders, low environmental variation, and access to refugia enhance reintroduction success across species (Clark et al. 2002). Additionally, low intraspecific competition and high rates of population increase with low population variance led to successful reintroductions (Griffith et al. 1989).

Secondly, from a genetics perspective, a successful reintroduction needs to avoid inbreeding depression and maintain a certain level of fitness to achieve the status of a self-sustaining population (Ewing et al. 2007). Inbreeding depression is the reduced survival and fertility of offspring of related individuals and results in an excess of homozygosity which can leave a population susceptible to deleterious mutations and overdominance (Charlesworth and Willis. 2009). However, when small numbers of individuals are reintroduced, the new population will generally have lower genetic diversity and not be representative of the source population's gene pool (Stockwell et al. 1996). Notably, many studies attribute genetic diversity (e.g., expected heterozygosity $\left(\mathrm{H}_{\mathrm{E}}\right)$ ) of a reintroduced population as the measurable indicator of a reintroduction success, often with the goal of maintained or higher genetic diversity than the source population (Sasmal et al. 2012, Jameison 2009, King et al. 2012). This is where a periodic, long-term assessment of genetic diversity post-reintroduction is encouraged nearly unanimously across studies (Ewing et al. 2007, Greenhorn et al. 2018, Stewart et al. 2017, Sasmal et al. 2012, Stockwell et al. 1996)

Thirdly, another consideration is connectivity and natural recolonization to augment, or in some cases support, rapid population growth post reintroduction. Typically, reintroductions are conducted in areas perceived as highly isolated, but natural recolonization is possible when systems demonstrate contemporary or near-future functional connectivity with adjacent 
populations (Stewart et al. 2017). Areas that may be considered extirpated could have a high propensity for natural recolonization following small population augmentation (via reintroductions), reconnecting metapopulations and leading to high population growth post reintroduction (Griffith et al. 1989, Stewart et al. 2017). When considering population fragmentation, long-term persistence is dependent on the recolonization of vacant patches of habitat following periodic local extinctions, which can be augmented with translocations (Clark et al. 2002).

Finally, the success of a reintroduction can look vastly different across species. However, since fisher are one of the most-widely reintroduced species in North America, we have much evidence regarding fisher behavior and demographics post-translocation (Drew et al. 2003). Across most fisher reintroductions, subsequent population growth and establishment of fisher into an ecosystem have often countered traditional expectations of a reintroduction. Stewart et al. (2017) studied the reintroduced population of fisher translocated from Manitoba and Ontario, and released in Alberta's Cooking Lake Moraine (CLM). It was assumed this release of individuals to CLM after 50 years of extirpation in most parts of Alberta founded the contemporary CLM population. However, after genotyping 147 CLM fisher, Stewart et al. (2017) found their CLM fisher were more highly related to populations further north than their source translocation individuals. This inspired further investigation of other fisher reintroductions in North America with genetic studies to measure reintroduction success, and Stewart et al. (2017) found that $47 \%$ of the time, genetic testing changed the status of a reintroduction as "successful" to an ambiguous contribution from the translocated individuals. This “ambiguous" status was even given to West Virginia's reintroduced fisher population after genetic assessment by Williams et al. (2000), where an allozyme-based assessment was used to 
compare contemporary West Virginia fisher to their source population. Another interesting result is from Greenhorn et al. (2018) studying population structure of fisher 10 years after recolonization in Ontario, Canada, to determine if homogenization among genetic clusters and northward migration had continued following recolonization. Surprisingly, there were no significant upper-level genetic structure changes towards homogenization, but they did find evidence of low-level genetic structure and a decrease of migration. Thirdly, Vinkey. et al. (2006) took a closer look at the fisher population erroneously thought to be extirpated from the northern Rockies, which led to five translocations of fisher to the Rockies between 1959 and 1991, resulting in a mix of native and introduced genetics. Reintroductions of fisher tend to act more as augmentations in areas with adjacent fisher populations, reconnecting the historical metapopulations of fisher in some cases.

While small reintroductions can lead to concerns of founder's effects and inbreeding, if a reintroduction is actually an augmentation of a cryptic population, introgressing genes from genetically distinct populations can sometimes be problematic (Tallmon et al. 2004). This is a common critique of genetic rescue (i.e., the introduction of immigrants to a population with the intention of improving fitness and alleviating inbreeding depression of a population) (Boher et al. 2005) due to concerns about augmentation/genetic rescue actually leading to outbreeding depression and driving down fitness (Tallmon et al 2004). An extreme example of this occurred when different subspecies of ibex were introduced to aid the recovery of an ibex population in Czechoslovakia, only for the resulting hybrid ibex to birth their calves too early, causing the entire population to disappear (Tempelton 1986).

As mentioned, West Virginia's reintroduction has been briefly reviewed using genetic data. Williams et al. (2000) examined four successful fisher reintroductions, including West 
Virginia's. Their study collected 18 fisher samples from the state and analyzed 20 allozyme loci, with results of 1.2 alleles/locus, 0.038 heterozygosity/locus and 0 unique alleles. Williams et al. (2000) discovered significant differences in allele frequencies between New Hampshire (source population) and West Virginia.

\section{Objectives}

The objectives of this chapter are to assess the genetic diversity of the West Virginia fisher population and compare it to PA, NY, and NH populations. I will use microsatellite data across the contemporary population of West Virginia fisher to determine genetic diversity and to identify existing vulnerabilities.

\section{Methods}

\section{DNA Extraction and Amplification}

The same overall methods for DNA extraction and amplification mentioned in Chapter 2 were also used for this chapter. All samples were amplified at the same nine loci for both Chapters 2 and 3 .

\section{Population Diversity}

Genetic diversity for all states was analyzed using the program GENEPOP v.4.2 (Rousset 2008) to determine levels of expected $\left(\mathrm{H}_{\mathrm{E}}\right)$ and observed $\left(\mathrm{H}_{\mathrm{O}}\right)$ heterozygosity of the populations and whether these values indicate a deviation from Hardy-Weinberg Equilibrium (HWE). These $\mathrm{H}_{\mathrm{E}}$ and $\mathrm{H}_{\mathrm{O}}$ values arise from exact Hardy-Weinberg tests of each locus in each population for which a null hypothesis (random union of gametes) is tested. Both values represent genetic diversity, a measure of genetic variation in a population (Weir 1996), and will be one of our estimates of genetic diversity in each state. I also determined allelic richness of each state population with genotype data in program GENEPOP. Significance of genetic diversity measures between West 
Virginia and New Hampshire populations was assessed with the Analysis Tool Pak add-on in Microsoft Excel using t-test of paired two sample for means, with each locus being a paired comparison.

\section{Effective Population Size}

Effective population size $\left(\mathrm{N}_{\mathrm{e}}\right)$ was calculated using the linkage disequilibrium method as implemented in the software NeEstimator V2.1 (Do et al. 2014).Effective population size represents the number of individuals genetically contributing to the next generation and is often less than the census population size. This variable is estimated using 10-20 microsatellite loci and samples of at least 25-50 individuals when the effective population size is less than 500 (Luikart et al. 2010). Effective population size was estimated for each state.

\section{Bottleneck Analysis}

Due to the small number of individuals $(n=23)$ reintroduced to West Virginia, I used program BOTTLENECK (Piry et al. 1999) to determine if the West Virginia population recently experienced a bottleneck. This program measures the expected heterozygosity distribution for all populations and loci under an assumption of mutation-drift equilibrium. The program was set to only calculate loci with allele frequencies greater than 0.02 using the Wilcoxon one-tailed test for heterozygote deficiency under a stepwise-mutation model.

\section{Results}

Six out of the nine microsatellite loci were out of HWE for West Virginia, based on the significance value $\alpha=0.05$. The 6 loci out of HWE all had a homozygote excess (Table 3 ). Only three of the nine loci were out of HWE in New Hampshire. The allelic richness $\left(\mathrm{A}_{\mathrm{r}}\right)$ for all nine microsatellite loci of West Virginia samples ranged from 2.20 to 4.31 , with a mean of 3.41 (Table 3). The range of $\mathrm{H}_{\mathrm{o}}$ for West Virginia is $0.106-0.740$, with a mean of 0.495 . The range of 
$\mathrm{H}_{\mathrm{E}}$ (gene diversity) for West Virginia is $0.115-0.733$, with a mean of 0.560 . The average $\mathrm{H}_{\mathrm{O}}$ and $\mathrm{H}_{\mathrm{E}}$ for New Hampshire are 0.490 and 0.623 , respectively (Table 3 ). These values were not significantly different for $\mathrm{H}_{\mathrm{O}}(\mathrm{p}=0.923)$ between West Virginia and New Hampshire, but were significant for $\mathrm{H}_{\mathrm{E}}(\mathrm{p}=0.046)$. Genetic diversity measures in West Virginia were similar to those observed in neighboring states.

The effective population size $\left(\mathrm{N}_{\mathrm{e}}\right)$ for West Virginia was estimated to be 94.5 with a $95 \%$ confidence interval by Jackknife of 83.4 to infinity. The $\mathrm{N}_{\mathrm{e}}$ for New Hampshire is -14.2 with a 95\% CI of 123.7 to infinity. The upper confidence intervals of infinity and the negative effective population size for New Hampshire is likely due to small sample size. The estimated effective population size for Pennsylvania $\left(\mathrm{N}_{\mathrm{e}}=108.5\right.$ (95\% CI: 84.7-141.2)) is likely to be the most accurate due to its large sample size. The estimated effective population size for West Virginia is not significantly different from Pennsylvania. However, there was evidence for a significant recent bottleneck in West Virginia's fisher population $(\mathrm{p}=0.014$; Table 4).

\section{Discussion}

The fisher population of West Virginia today is primarily the result of reintroduction translocations between 1969-1998 that brought new individuals from New Hampshire to West Virginia, where fisher had been extirpated. It is clear recolonization and migration are typically recorded post fisher reintroductions (Stewart et al. 2017, Vinkey et al. 2006), which likely led this central-northeastern population to its contemporary population size across West Virginia, Pennsylvania and parts of New York and New Hampshire today (Larkin et al. 2011). However, uncertainty remained about whether the 1969 reintroduction of 23 fisher to West Virginia to start a contemporary fisher population in this historic range was successful. 
A self-sustaining population is typically synonymous with a successful reintroduction. West Virginia fisher are estimated to be 1000-2000 individuals contemporarily, with about 100 individuals harvested in the state each year (Williams et al. 2000, personal communication, Rich Rogers, WVDNR). Additionally, the effective population size $\left(\mathrm{N}_{\mathrm{e}}\right)$ is estimated at 94.5 individuals in West Virginia (Table 4). The observed ratio of effective population size and census population size $\left(\mathrm{N}_{\mathrm{e}} / \mathrm{N}\right)$ has been found to be $10-20 \%$, and when census size is unknown typically $10 \%$ is assumed (Frankham 2009). Thus, with $\mathrm{N}_{\mathrm{e}}=94.5$ we can estimate the census population to be $\mathrm{N}=945$, close to the low end of the estimated range of fisher in West Virginia. Since the extirpation of fisher from West Virginia by 1912, and a single reintroduction event of 23 individuals, there is now an estimated 1000-2000 individuals of this self-sustaining population, supported by $\mathrm{N}_{\mathrm{e}}$ estimates. Consecutive, yearly trapper harvest opened since 1972 also provides evidence of a self-sustaining population (Lesser and Cromer 2015).

The other important consideration when determining whether a reintroduction is successful are reports of genetic diversity inherent in a population. West Virginia's average $\mathrm{H}_{\mathrm{E}}$ (gene diversity) is 0.56 , compared to New Hampshire's average gene diversity of 0.623 (Table 3). While the observed heterozygosity $\left(\mathrm{H}_{\mathrm{O}}\right)$ was not significantly different, the expected diversity $\left(\mathrm{H}_{\mathrm{E}}\right)$ in West Virginia, which is our report of gene diversity, was significantly lower than New Hampshire $(\mathrm{p}=0.045)$. Thus, the gene diversity of the reintroduced West Virginia population is significantly different than its source population from New Hampshire, contemporarily (Table 3). Loss of genetic diversity may occur from 1) the extinction of alleles due to sampling in small populations, 2) inbreeding causing a reduction of heterozygosity by distributing gene diversity among homozygous individuals and populations) or 3) selection favoring one allele at the cost of 
others leading to fixation, which in our case is unlikely since microsatellites are neutral markers (Frankham et al. 2002, Allendorf and Luikart 2007).

The first reason, extinction of alleles due to sampling in small populations, can be supported by the evidence of a bottleneck in West Virginia. This was one of our hypotheses, that this population, founded by 23 individuals with no genetic information or comparison during sampling, has resulted in a founder's effect for this now large and relatively established population. This evidence of bottleneck does not necessarily condemn the West Virginia population; many genetic studies with temporal components found that significant changes in genetic diversity occur in wild populations over relatively short time periods (Greenhorn et al. 2018). However, it is likely the continued migration into the West Virginia population from other nearby populations has helped to combat this bottleneck effect.

The second reason, that inbreeding has caused a reduction in heterozygosity, may be related to the many loci that are out of HWE in West Virginia (Table 3). Deviations in HWE indicate a population is not a large random mating population at equilibrium and may be subject to selection, genetic drift or migration. Thus, our 6 out of 9 loci deviations from HWE, all with homozygous excess, in West Virginia could be a result of a violation of these assumptions of equilibrium, or possibly due to sampling error such as selection bias, population stratification or genotyping error (Namopashaki et al. 2015). However, MICROCHECKER was run on the genotype data with no concerning alleles so genotyping error is unlikely in our case. A population is in HWE when there is no migration (gene flow), no natural selection, no mutation, each member of the population is equally likely to breed, the population is infinitely large, and there is full random mating (Smith and Baldwin. 2015). Therefore, any one of these reasons could be violated in the West Virginia population, for example gene flow between neighboring 
populations, the presence of multiple genetic populations (i.e., Wahlund effect) or the presence of inbreeding, causing the West Virginia population to deviate from HWE. The small population size $(n=23)$ of individuals translocated during the reintroduction combined with contemporary effective population size estimates $\left(\mathrm{N}_{\mathrm{e}}=94\right)$ may be a significant contributor to the deviations in HWE seen by 6 of the 9 loci in this population.

It is possible this loss of gene diversity from the source New Hampshire population $\left(\mathrm{H}_{\mathrm{E}}=0.623\right)$ to West Virginia $\left(\mathrm{H}_{\mathrm{E}}=0.56\right)$ is due to one or more of these reasons. While we can see a reduction in gene diversity from the population our reintroduction was sourced from over 50 years ago, in general the $\mathrm{H}_{\mathrm{E}}=0.56$ in West Virginia supports a high level of gene diversity for fisher (Tucker et al. 2012, Lucid et al. 2019, Greenhorn et al. 2018). Similar gene diversity is seen in the Pennsylvania population $\left(\mathrm{H}_{\mathrm{E}}=0.548\right)$ which can be indicative of West Virginia and Pennsylvania level of gene flow and recolonization by the same remnant population(s). This can be supported by Pennsylvania agencies reporting expansion of fisher in the southern portion of the state following the West Virginia reintroduction. Also, the higher level of gene diversity for New Hampshire and New York support why these populations are maintained as source populations for several North American fisher reintroductions to Wisconsin, West Virginia, Connecticut, and Pennsylvania (Williams et. al 2000, Drew et al. 2003, Hapeman et al. 2011).

The final measure of genetic diversity comes from the allelic richness results. Allelic richness $\left(A_{R}\right)$ is a measure of genetic diversity indicative of a population's long-term potential for persistence and adaptability (Greenbaum et al. 2014). West Virginia's allelic richness ( $\mathrm{A}=3.409)$ is closer to that of New Hampshire ( $A=3.452)$ than neighboring state Pennsylvania $(A=3.262)$, possibly representing the single reintroduction to West Virginia from New Hampshire, versus the multiple reintroductions from New York and one from New Hampshire to Pennsylvania. Since 
none of the allelic richness reports are significantly different from each other, allelic richness can be considered similar across all four states and has not been impacted negatively either by extirpation, reintroductions or recolonization.

While the effective population size $\left(\mathrm{N}_{\mathrm{e}}\right)$ for West Virginia fisher at 94.5 may support a self-sustaining population, it is important to recognize several variables can affect $\mathrm{N}_{\mathrm{e}}$. Variables such as spatial dispersion, breeding sex ratio, and fluctuating population size can influence $\mathrm{N}_{\mathrm{e}}$ and $\mathrm{N}_{\mathrm{e}}$ can also predict the extinction risk of a population (Luikart et al. 2010). This $\mathrm{N}_{\mathrm{e}}=94.5$ is above the "50" individuals needed to avoid inbreeding depression but below the "500" needed to maintain long-term evolutionary potential from the 50/500 rule associated with $\mathrm{N}_{\mathrm{e}}$. Franklin (1980) proposed the 50/500 rule for minimum viable population (MVP). Being at risk for not maintaining long-term evolutionary potential does not discredit the evidence of a contemporary self-sustaining population in West Virginia. However, a larger sample size could reveal a more accurate $\mathrm{N}_{\mathrm{e}}$ for the West Virginia fisher population. The effective population size of New Hampshire is negative $\left(\mathrm{N}_{\mathrm{e}}=-14.2\right)$, and therefore cannot be interpreted. This is due to the very small sample size $(\mathrm{N}=13, \mathrm{~N}<50)$. The $\mathrm{N}_{\mathrm{e}}$ for Pennsylvania $\left(\mathrm{N}_{\mathrm{e}}=109\right)$, and New York $\left(\mathrm{N}_{\mathrm{e}}=31\right)$ are also under the long-term "500" threshold. Additionally, this comparable $\mathrm{N}_{\mathrm{e}}$ between West Virginia and Pennsylvania helps combat the possible impact of a bottleneck. 


\section{Chapter 4: Management Implications}

Managing a reintroduced population is crucial to ensure the efforts of the reintroduction result in a self-sustaining population (Griffith et al. 1989). Typically, managers are looking for a selfsustaining population in terms of demographics and population size. The reintroduction of fisher in West Virginia by the West Virginia Division of Natural Resources (WVDNR) occurred in the winter of 1969 following the decades long extirpation of the species from the states since 1912 (Lesser and Cromer 2015). Since the reintroduction, WVDNR considered this an established population of fisher with approximately 1000-2000 individuals and evidence of expansion into neighboring states Pennsylvania and Maryland (personal communication, Rich Rogers, WVDNR). The expansion within the state occurred largely from the Tucker Co. release of 15 individuals where rapid expansion into the Monongahela National Forest occurred, and little to no expansion occurred at the Pocahontas Co. release of 8 individuals (Cromer 2002, Figure 1).

However, WVDNR managers recognized the need to assess the genetic status of this reintroduced fisher population and moved forward with this study. In the previous chapters, I discussed the results of genetic analysis of 459 fisher samples from West Virginia $(n=87)$, Pennsylvania $(n=340)$, New York $(n=22)$ and New Hampshire $(n=13)$. Significant results are that there are three genetic populations across all four states and three genetic populations in West Virginia (Figure 4, Figure 5). The genetic diversity of West Virginia's samples are significantly less $(\mathrm{p}=0.046)$ than the diversity of New Hampshire, the source population for West Virginia's reintroduction. Additionally, the location and sample size of individuals released to Tucker. Co. resulted in the contemporary re-establishment of fisher in the state, but the result of 5 private alleles is evidence for cryptic, remnant individuals, which persisted unobserved by 
managers, resurging only after the reintroduction event. There is not a significant genetic difference between male and females sampled in this study.

Based on numerous previous fisher studies and general wildlife reintroduction assessments, West Virginia's fisher population has successfully established since translocation, likely driven by successful reintroductions and the resurgence of cryptic, remnant individuals. The breadth of three distinct populations spread across four states is likely a result of founder events following reintroductions. Thus, it is not necessary to manage the fisher as three separate populations, but rather to recognize they were founded from historical reintroductions. There could have also been remnant individuals/populations of fisher supporting contemporary gene flow and connectivity within populations. Through these results, I have uncovered an easterncentral metapopulation, shaped by historic translocation events that provided founding genetic diversity to three contemporary population groups.

Our goal was to determine if this reintroduction was successful, based on contemporary genetic diversity of the West Virginia population. The evidence supports that West Virginia's population has captured some genetic diversity but does not exceed the source population's diversity following the 1969 reintroduction, which by some reports may consider the reintroduction "unsuccessful" (Excoffier et al. 2009). However, since evidence of the New Hampshire population persists in West Virginia based on population distinctions, this reintroduction should be considered successful (Stewart et al. 2017). Since West Virginia has significantly lower gene diversity than New Hampshire, the 23 individuals that were translocated in 1969 may not have captured the full genetic diversity of New Hampshire at the time. The diversity we do see is possibly augmented by remnant populations in the state and migration from nearby states (Stewart et al. 2017), but appears to represent the historic reintroduction 
events of the study area. It is unlikely the diversity sampled in this population today is solely from the 23 individuals released in 1969. The reality is that migration, gene flow and natural recolonization was able to support a metapopulation founded on reintroduction events from 1969-1998 in West Virginia and Pennsylvania. Most reintroduction studies emphasize the need for continued genetic monitoring to ensure long-term population viability (Ewing et al. 2007, Greenhorn et al. 2018, Stewart et al. 2017, Sasmal et al. 2012, Stockwell et al. 1996). That is still true in this case. While we now have a much better understanding of what the contemporary genetic diversity looks like 50 years after reintroductions, reporting any loss of diversity as it happens is the best way to combat long-term negative effects such as inbreeding depression. This "snapshot" of genetic diversity gives evidence that fisher reintroductions can result in relatively ambiguous contemporary populations, but continued monitoring will likely reveal when/if the population needs further augmentation (Stewart et al. 2017, Williams et al. 2000). At this time, it does not appear augmentation is necessary, but the strong evidence of a recent bottleneck and significantly lower diversity from the source population could be used as a jumping point to consider translocations to West Virginia in the future.

If augmentation is considered, I suggest following the evidence of the 1969 reintroduction to determine how many individuals and where in the state to conduct reintroductions/translocations. The release of 15 individuals in Tucker Co. resulted in rapid expansion whereas 8 individuals released in Pocahontas Co. resulted in no expansion or contemporary establishment of that area (Figure 1). Many studies point to initial size released to be greatly influential on the success of a reintroduction (Griffith et al. 1989, Kromers and Curman 2000, Clark et al. 2002). Another consideration is the Allee effect, which results when very few individuals are around for mating which reduces the rate of reproduction and lowers 
genetic diversity. I suggest at least 15 individuals, but recommend the highest number possible, be released at one site during a future augmentation. Since there was no significant difference between males and females sampled, it should not be high priority to obtain more of one sex than the other for an augmentation. The level of relatedness was only significant between New York and New Hampshire, thus an augmentation from Pennsylvania, New York or New Hampshire to West Virginia should not have concern for being highly related to contemporary West Virginia fisher. Additionally, we have evidence of cryptic, remnant individuals persistent during the 1969 reintroduction. For this reason, I suggest pursuing fisher surveys throughout the state. Any evidence of fisher existing, even through reported observations, could provide additional breeding individuals needed to re-establish populations and combat the Allee effect in new areas of the state.

Fisher are back in West Virginia after continent-wide range constriction and extirpations. The fisher is a harvested furbearer in the state, though primarily limited to the northeastern part of the state (Figure 1). Restoring fisher populations to original range of the entire state (Lewis et al. 2012) would be a reasonable goal. With careful survey and record data, it might be possible to introduce new augmentation efforts. Since West Virginia's fisher genetic diversity is lower than its source population, it should also be a top priority to assess any potential individuals for translocation for genetic diversity and relatedness to the current West Virginia population. This is to ensure genetic diversity is maximized in the state for species viability and the greatest longterm evolutionary potential. Other factors such as public perception and habitat suitability will also need to be assessed before a translocation can occur.

\section{Literature Cited}


Allendorf, FW., and G. Luikart. (2007) Conservation and the genetics of populations. Blackwell Publishing, USA.

Baker, A.J., and A. Moeed. 1987. Rapid genetic differentiation and founder effect in colonizing populations of common mynas Acridotheres tristis. Evolution 41, 525-538.

Bell, R. 2018. Martes Pennanti Fisher. Wild Ohio Explorer.

Bertrand, P., Bowman, J., Rodney, J.D., Manseau, M, and P.J. Wilson. 2017. Sex-specific graphs: Relating group-specific topology to demographic landscape data. Molecular Ecology 26: 3898-3912.

Blachong, J., K. Scribner, and S. Winterstein. 2002. Assignment of individuals to populations: Bayesian methods and multi-locus genotypes. Journal of Wildlife Management 66: 321329.

Boher, G., Nathan, R., and S. Volis. 2005. Effects of long-distance dispersal for metapopulation survival and genetic structure at ecological and spatial scales. British Ecology Society 93: 1029-1040.

Bray, S. and J. Mulle, A. Dodd, A. Pulver, S. Wooding, S. Warren. 2010. Signatures of founder effects, admixture, and selection in the Ashkenazi Jewish population. PNAS 107:1622216227.

Brekke, P., P. Bennett, J. Wang, N. Pettorelli and J. Ewen. 2010. Sensitive males: inbreeding depression in an endangered bird. Proceedings of the Royal Society 277: 3677-3684.

Carr, D., Bowman, J. and P.J. Wilson. 2007. Density-dependent dispersal suggests a genetic measure of habitat suitability. Oikos 116: 629-635. 
Carr, D., Bowman, J., Kyle, C.J., Tully, S.M., Koen, E.L., Robitaille, J.F., and P.J. Wilson. 2007. Rapid homogenization of multiple sources: genetic structure of a recolonizing population of fisher. Wildlife Management 71: 1853-1861.

Charlesworth, D. and J. Willis. 2009. The genetics of inbreeding depression. Nature Reviews Genetics 10: 783-796.

Clark, J., Huber, D., and C. Servheen. 2002. Bear reintroductions: lessons and challenges. Ursus 13: $335-345$.

Clarke, M. and Schedvin, N. 1996. An experimental study of the translocation of noisy miners Manoria melanocephala and difficulties associate with dispersal. Biological Conservation. 80: 161-167.

Clegg S.M., Degnan S.M., Kikkawa J. et al. 2002. Genetic consequences of sequential founder events by an island-colonizing bird. Proceedings of the National Academy of Sciences 99: 8127-8132.

Cullingham, C. I., and A. Moehrenschalger. 2013. Temporal analysis of genetic structure to assess population dynamics of reintroduced swift foxes. Conservation Biology 27:13891398.

Dalen, I., Kvaloy, K. Linnell, J.D., Elmhagen, B., Strand, O., Tannerfeldt, M., Henttonen, H., Fuglei, E., Landa, A., Angerbjorn, A. 2006. Population structure in a critically endangered arctic fox population: does genetics matter? Molecular Ecology 15: 28092819. 
Davis, C. and C. Strobeck. 1998. Isolation, variability, and cross-species amplification of polymorphic microsatellite loci in the family Mustelidae. Molecular Ecology 7: 17711778.

De Barba, M., Waits, L.P., Garton, E.O., Genovesi, P., Randi, E., Mustoni, A., and C. Groffs. 2010. The power of genetic monitoring for studying a demography, ecology and genetics of a reintroduced brown bear population. Molecular Ecology 19: 3938-3951.

Drew, R.E., Hallett, J.G., Aubry, K.B., Cullings, K.W., Koepfs, S.M., and J. Zielinski. 2003. Conservation genetics of the fisher (Martes pennanti) based on mitochondrial DNA sequencing. Molecular Ecology 12: 51-62.

Do, C., Waples, R. S., Peel, D., Macbeth, G. M., Tillett, B. J. \& Ovenden, J. R. 2014. NeEstimator V2: re-implementation of software for the estimation of contemporary effective population size (Ne) from genetic data. Molecular Ecology Resources 14: 209214

Doerner, K.C., Braden, W., Cork, J., Cunningham, T., Rice, A., Furman, B., and D. McElroy. 2005. Population genetics of resurgence: white-tailed deer in Kentucky. Journal of Wildlife Management 69: 345-355.

Ellington, E. H. 2010. Developing habitat models to predict fisher occupancy in Pennsylvania. M.S. Thesis, Indiana University of Pennsylvania, Indiana, Pennsylvania, 105 p.

Ewen, J. and D. Armstrong. 2007. Strategic monitoring of reintroductions in ecological restoration programmes. Ecoscience. 14: 401-409. 
Ewing, S., Nager, R., Nicoll, M., Aumjaud, A., Jones, C., and L. Keller. 2007. Inbreeding and loss of genetic variation in a reintroduced population of Mauritius kestrel. Conservation Biology 22: 395-404.

Excoffier, L., Foll, M., and R.J. Petit. 2009. Genetic consequences of range expansion. Annual Review of Ecology, Evolution and Stystematics 40: 481-501.

Frankham, R. 2009. Effective population size/adult population size ratios in wildlife: a review. Cambridge University Press.

Frankham, R.., Ballou, J.D., and D. Briscoe. 2002. Introduction to conservation genetics. Cambridge University Press, Cambridge

Franklin, I. R. 1980. Evolutionary change in small populations. Conservation biology: an evolutionary-ecological perspective 135-149.

Friar E.A., Landoux T., Roalson E.H., Robichaux R.H. 2000. Microsatellite analysis of a population crash and bottleneck in the Mauna Kea silversword, Argyroxiphium sandwicense ssp. sandwicense (Asteraceae), and its implications for reintroduction. Molecular Ecology 9: 2027-2034

Gallardo-Alvarez, M., J. Lesher-Gordillo, S. Machkour-M'Rabet, C. Zenteno-Ruiz, L. OliveraGomez, M. Barragan-Vazquez, L. Rios-Radas, A. Valdes-Marin, H. Vazquez-Lopez, and S. Arriaga-Weiss. 2019. Genetic diversity and population structure of founders from wildlife conservation management units and wild populations of critically endangered Dermatemys mawii. Global Ecology and Conservation 19.

Garroway, C.J., Bowman, J., Carr, D., and P.J. Wilson. 2008. Applications of graph theory to landscape genetics. Evolutionary Applications 1: 620-630. 
Greenbaum, G., Templeton, A., Zarmi, Y., and S. Bar-David. 2014. Allelic richness following population founding events - a stochastic modeling framework incorporating gene flow and genetic drift. Plos One 9.

Greenhorn, J.E., Bowman, J., and P.J. Wilson. 2018. Genetic monitoring suggests increasing structure following recolonization by fishers. Journal of Wildlfe Management 82: 14031416.

Griffith, B., Scott, M., Carpenter, J., and C. Reed. 1989. Translocation as a species conservation tool: status and strategy. American Association for the Advancement of Science. 245: 477480.

Habel, J. N., \& Zachos, F. E. (2013). Past population history versus recent population declineFounder effects in island species and their genetic signatures. Journal of Biogeography 40: 206-207

Hampton, J., P. Spencer, D. Alpers, L. Twigg, A. Woolnough, J. Doust, T. Higgs, and J. Pulske. 2004. Molecular techniques, wildlife management and the importance of genetic population structure and dispersal: a case study with feral pigs. Journal of Applied Ecology 41: 735-743.

Hapeman, P., Latch, E.K., Fike, J.A., Rhodes, O.E., and C.W. Kilpatrick. 2011. Landscape genetics of fishers (Martes pennanti) in the Northeast: dispersal barriers and historical influences. Journal of Heredity 102: 215-259.

Hawley, D.M, Hanley, D., Dhont, A.A., and I.J. Lovette. 2005. Molecular evidence for a founder effect in invasive house finch (Carpodacus mexicanus) populations experiencing emergent disease epidemic. Molecular Ecology 15: 263-275. 
Hicks, J.T., Rachlow, J.L., Rhodes, O.E., Christen, L., and L.P. Waits. 2007. Reintroduction and genetic structure: Rocky Mountain elk in Yellowstone and western states. Mammology 88: $129-138$.

Hufbauer R.A., Bogdanowicz S.M., and Harrison R.G. 2004. The population genetics of a biological control introduction: mitochondrial DNA and microsatellite variation in native and introduced populations of Aphidus ervis, a parasitoid wasp. Molecular Ecology 13: $337-348$.

Hundertmark, K. and L. Van Daele. 2010. Founder effect and bottleneck signatures in an introduced, insular population of elk. Conservation Genetics 11: 139-147.

IUCN. 1995. IUCN/SSC Guidelines for re-introductions. Forty-first meeting.of the IUCN council, Gland, Switzerland. May 1995. 6 p.

Jameison, I. 2010. Founder effects, inbreeding, and loss of genetic diversity in four avian reintroduction programs. Conservation Biology 25: 115-123.

Johnson, J., M. Bellinger, J. Toepfer, and P. Dunn. 2004. Temporal changes in allele frequencies and low effective population size in greater prairie-chickens. Molecular ecology 13: 2617-2630.

Jordan, M., M. Higley, S. Matthews, O. Rhodes, M. Schwartz, R. Barrett, and P. Palsboll. 2007. Development of 22 new microsatellite loci for fishers (Martes pennanti) with variability results from across their range. Molecular Ecology Notes 7: 797-801.

Keating, A. 2017. The elusive fisher. New Hampshire Wildlife Journal 12-16. 
Keller, L. F., K. J. Jeffery, P. Arcese, M. A. Beaumont, W. M. Hochachka, J. N. M. Smith, and M. W. Bruford. 2001. Immigration and the ephemerality of a natural population bottleneck: evidence from molecular markers. Proceedings: Biological Sciences 268:1387-1394.

Knapp, E. and P. Connors. 1999. Genetic consequences of a single-founder population bottleneck in Trifolium amoenum (Fabacae). American Journal of Botany 86: 124-130.

Komers, P.E. and G.P. Curman. 2000. The effect of demographic characteristics on the success of ungulate re-introductions. Biological Conservation 93: 187-193.

Kruckenhauser, L., and W. Pinsker. 2008. Microsatellite variation in autochthonous and introduced populations of the Alpine marmot (Marmota marmota) along a European west-east transect. Zoological Systematics and Evolutionary Research 42: 19-26.

Kyle, C., J, Robitaille, and C. Strobeck. 2001. Genetic variation and structure of fisher (Martes pennanti) populations across North America. Molecular Ecology 10: 2341-2347.

La Haye, M., Reiners, T., Raedts, R., Verbists, V., and H. Koelewijn. 2017. Genetic monitoring to evaluate reintroduction attempts of a highly endangered rodent. Conservation Genetics 18: 877-892.

Larkin, J., Gabriel, M., Gerhold, R.W., Yabsley, M.J., Wester, J.C., Humphreys, J.G, Beckstead, R., and J.P. Dubey. 2011. Prevalence to Toxoplasma gondii and Sarcocystis spp. in a reintroduced fisher (Martes pennanti) population in Pennsylvania. Journal of Parasitol 97: 425-429. 
Larkin, J., Wester, J., Cottrell, W. and M. DeVivo. 2010. Documentation of the rabies virus in free-ranging fisher (Martes pennanti) in Pennsylvania. Northeastern Naturalist 17: 523530.

Lewis, J.C., Powell, R.A., and W.J. Zielinski. 2012. Carnivore translocations and conservation: insights from population models and field data for fishers (Martes pennanti). Plos One 7:3.

Linden, D.W., and A.K. Fuller, J.A. Royle, M.P. 2017. Hare. Examining the occupancy-density relationship for a low-density carnivore. Journal of Applied Ecology 56.

Lucid, M., Rankin, A., Sullivan, J., Robinson, L., Ehlers, S., and S. Cushman. 2019. A carnivores' oasis? An isolated fisher (Pekania pennanti) population provides insight on persistence of a metapopulation. Conservation Genetics 20: 585-596.

Luikart, G., Ryman, N., Tallmon, D., Schwartz. K., and F. Allendorf. 2010. Estimation of census and effective population sizes: the increasing usefulness of DNA-based approaches. Conservation Genetics 11: 355-373.

Marandel, F., Charrier, G., Lamy, J., Le Cam, S., Lorance, P., and V, Trenkel. 2019. Estimating effective population size using RADseq: effects of sNP selection and sample size. Ecology and Evolution 10: 1929-1937.

McCance, S., N. Kahn, K. Burnham, C. Brauns, and T. Quinn. 1999. A population genetic comparison of large- and small-bodied sage grouse in Colorado using microsatellite and mitochondrial DNA markers. Molecular Ecology 8: 1457-1465. 
McCoy, John. Reintroduced in late 1960s, fisher fare fine in WV. Charleston Gazzete-Mail. Published 27 May 2017. Web accessed wvgazettemail.com.

Moncrief, N. and M. Fies. 2015. Report of first specimens of Pekania pennanti (Fisher) from Virginia. Northeastern Naturalist 22: 4.

Muller, L., Murrow, J., Lupardus, J., Clark, J., Yarkovich, J., Stiver, W., Delozier, E., Slabach, B., Cox, J., and B. Miller. 2018. Genetic structure in elk persists after translocation. Journal of Wildlife Management 82: 1124-1134.

Namipashaki A, Razaghi-Moghadam Z, Ansari-Pour N. 2015. The Essentiality of Reporting Hardy-Weinberg Equilibrium Calculations in Population-Based Genetic Association Studies. Cell Journal 17:187-92.

Neel, M. and M. Cummings. 2003. Effectiveness of conservation targets capturing genetic diversity Conservation Biology 17: 219-229.

Nei, M. 1972 Genetic distance between populations. American Naturalist 106.

Nei, M., Takeo, M., and R. Chakraborty. 1975. The bottleneck effect and genetic viability in populations. International Journal of Organic Evolution. 29: 1-10.

New York State Department of Environmental Conservation (NYSDEC). 2015. New York State Fisher Management Plan. Albany, NY.

Orff, Eric. The fisher: New Hampshire's Rodney Dangerfield. Solving Problems with NatureNaturally.

Pray, L. 2008. Genetic drift: bottleneck effect and the case of the bearded vulture. Nature Education 1:61 
Pennsylvania Game Commission, Bureau of Information and Education. 2016. Fisher Note. Harrisburg, PA.

Powell R.A., and W.J. Zielinski. 1994. Fisher. Pages 38-37. The scientific basis for conserving forest carnvifores, American marten, fisher, lynx, and wolverine in the western United States, Rocky Mountain forest and Range Experiment Station Gnereal Technical Report RM-254, Fort Collins, CO, USA.

Pruett C.I. and Winker K. 2005. Northwestern song sparrow populations show genetic effects of sequential colonization. Molecular Ecology 14: 1421-1434.

Reding, D. and Carter, C., Hiller, T., Clark, W. 2013. Using population genetics for management of bobcats in Oregon. Wildlife Society Bulletin 37: 342-351.

Robert, A., Colas, B., Guigon, I., Kerbiriou, C., Mihoub, J-B., Saint-Jalme, M. and F. Sarrazin. 2015. Defining reintroduction success using IUCN criteria for threatened species: a demographic assessment. Animal Conservation 18: 397-406.

Russel, W., Thorne, T., Oakleaf, R., and J. Ballou. 1994. The genetic basis of black-footed ferret reintroduction. Conservation Biology 8: 263-266.

Sasmal, I., Jenks, J., Waits, L., Gonda, M., Schroeder, G., and S. Datta. 2013. Genetic diversity in a reintroduced swift fox population. Conservation Genetics 14: 93-102

Schwartz, T. and S. Karl. 2006. Population genetic assignment of confiscated gopher tortoises. Management and Conservation 72: 254-259.

Schwartz, M. K., G. Luikart, and R. S. Waples. 2007. Genetic monitoring as a promising tool for conservation and management. Trend in Ecology and Evolution 22: 25-33. 
Seddon, P.J., Armstrong, D.P., and R. Maloney. 2007. Developing the science of reintroduction biology. Conservation Biology 21: 303-312.

Smith, M. and J. T. Baldwin. 2015. Making Sense of Hardy-Weinberg Equilibrium. The American Biology Teacher 77: 577-582.

Spencer, W., Rustigian-Rosmos, H., Strittholt, J., Scheller, R., Zielinski, W., and R. Truex. 2010. Using occupancy and population models to assess habitat conservation opportunities for an isolated carnivore population. Biological Conservation 144: 788-803.

Stewart, F.E., Volpe, J.P., Taylor, J.S., Bowman, J., Thomas, P.J., Pybus, M.J., and J.T. Fisher. 2017. Distinguishing reintroductions from recolonization with genetic testing. Bioogical Conservation 214: 242-249.

Stuhmiller, J. The Ever So Adaptable Fisher. Animals and Plants of the Finger Lakes.

Saunders, D. A. 1988. Fisher (Martes pennanti Erxleben). Adirondack Mammals.

Tallmon, D., Luikart, G., and R. Waples. 2004. The alluring simplicity and complex reality of genetic rescue. Trends in Ecology and Evolution 9: 490-496.

Tarr C.L., Conant S., Fleischer R.C. 1998. Founder events and variation at microsatellite loci in an insular passerine bird, the Laysan finch (Telespiza cantans). Molecular Ecology 7: $719-731$.

Templeton AR (1986) Coadaptation and outbreeding depression. In: Conservation Biology: The Science of Scarcity and Diversity (ed. Soule M), pp. 105-116. Sinauer Assoc., Sunderland, Massachusetts 
Tucker, J. M., F. W. Allendorf, R. L. Truex, and M. K. Schwartz. 2017. Sex-biased dispersal and spatial heterogeneity affect landscape resistance to gene flow in fisher. Ecosphere 8:6

Tucker, Jody M., Schwartz, M.k., Truex, R.L., Wisely, S.M., and F. W. Allendorf. 2014. Sampling Affects the Detection of Genetic Subdivision and Conservation Implications for Fisher in the Sierra Nevada. Conservation Genetics 15:123-136.

Vinkey, R., Schwartz, M., McKelvey, K., Foresman, K., Pilgrim, K, Giddings, B., ad E. LoFroth. 2006. When reintroductions are augmentations: the genetic legacy of fishers (Martes pennanti) in Montana. Journal of Mammalogy 87: 265-271.

Welsh, A., T hill, H. Quinlan, C. Robinson, and B. May. 2008. Genetic Assessment of Lake Sturgeon Population Structure in the Laurentian Great Lakes. North American Journal of Fisheries Management 28: 572-591.

Wen, Z., K. Pollock, J. Nichols, and P. Waser. 2011. Augmenting Superpopulation CaptureRecapture Models with Population Assignment Data. Biometrics 67: 691-700.

Weir. B. Genetic Data Analysis II. Sundarland, Mass. Sinauer Associates. 1996.

Weir, B. S., and C. Clark Cockerham. 1984. Estimating F-Statistics for the Analysis of Population Structure. Evolution 38: 1358-1370.

Williams, B.W., Gilbert, J.H., and P.A. Zollner. 2006. Historical perspective on the reintroduction of the fisher and American marten in Wisconsin and Michigan. United States Department of Agriculture.

Williams, R.N., Rhodes, O.E., and T.L. Serfass. 2000. Assessment of genetic variance among source and reintroduced fisher populations. Journal of Mammalogy 81: 895-907. 
Williams, R.N., Page, K, Sefrass, T.L., and O.E. Rhodes. 1999. Genetic polymorphisms in Fishers (Martes pennanti)

Williams, W. Fisher Information. Pennsylvania Trappers Association.

Wilson, G., Fulton, T., Kendell, K., Scrimgeour, G., Paszkowski, C., and D. Coltman. 2008. Genetic diversity and structure in Canadian northern leopard frog (Rana pipiens) populations: implications for reintroduction programs. Canadian Journal of Zoology 86: 863-874.

Wisely, S., S. Buskirk, G. Russell, K. Ahbry, and W. Zielinski. 2004. Genetic diversity and structure of the fisher (Martes pennanti) in a peninsular and peripheral metapopulation. Journal of Mammalogy 85: 640-648 


\section{Tables}

Table 1. Percentages of admixture per population when measured as 0.8 or higher $(\mathrm{A}, \mathrm{B}, \mathrm{C})$, and any sample measuring under 0.8 , admixture measured as the next top two populations $(\mathrm{AB}, \mathrm{BC}$, $A C)$.

\begin{tabular}{l|clllll}
\multicolumn{1}{c}{} & $\mathrm{A}$ & $\mathrm{AB}$ & $\mathrm{B}$ & $\mathrm{BC}$ & $\mathrm{C}$ & $\mathrm{AC}$ \\
\hline West Virginia & $23.8 \%$ & $3.6 \%$ & $11.9 \%$ & $2.4 \%$ & $47.6 \%$ & $10.7 \%$ \\
Pennsylvania & $31.2 \%$ & $15.1 \%$ & $47.5 \%$ & $3.3 \%$ & $0.6 \%$ & $2.4 \%$ \\
New York & $36.4 \%$ & $13.6 \%$ & $4.5 \%$ & $13.6 \%$ & $27.3 \%$ & $4.5 \%$ \\
New Hampshire & $53.8 \%$ & $0.0 \%$ & $23.1 \%$ & $7.7 \%$ & $0.0 \%$ & $15.4 \%$
\end{tabular}

Table 2 FST $_{\text {ST }}$ pairwise analysis of sample populations from 4 geographically inferred fisher populations. Shaded cells indicated associated p-values with an alpha of 0.05. Significance denoted with “*”. Values above the diagonal are the FST value, and values below the diagonal are associated p-values (alpha $=0.05)$.

\begin{tabular}{|c|c|c|c|c|}
\hline & West Virginia & Pennsylvania & New York & New Hampshire \\
\hline West Virginia & 0 & 0.036 & 0.060 & 0.035 \\
\hline Pennsylvania & $0.008^{*}$ & 0 & 0.064 & 0.038 \\
\hline New York & $0.008 *$ & $0.008^{*}$ & 0 & 0.013 \\
\hline New Hampshire & $0.008^{*}$ & $0.008^{*}$ & 0.142 & 0 \\
\hline
\end{tabular}

Table 3 Genetic diversity measured as observed heterozygosity $\left(\mathrm{H}_{\mathrm{O}}\right)$ and expected heterozygosity $\left(\mathrm{H}_{\mathrm{E}}\right)$ per locus per state population from program GENEPOP. Locus results with (*) indicate the locus is out of Hardy-Weinberg Equilibrium (HWE). Allelic richness $\left(\mathrm{A}_{\mathrm{r}}\right)$ per locus and population based on minimum sample size of 8 diploid individuals from program GENEPOP. 


\begin{tabular}{|c|c|c|c|c|c|c|c|c|c|c|}
\hline & \multicolumn{3}{|c|}{ West Virginia } & \multicolumn{3}{|c|}{ Pennsylvania } & \multicolumn{3}{|c|}{ New York } & \multirow[b]{2}{*}{$\mathrm{H}_{\mathrm{O}}$} \\
\hline Locus & $\mathrm{H}_{\mathrm{O}}$ & $\mathrm{H}_{\mathrm{E}}$ & A & $\mathrm{H}_{\mathrm{O}}$ & $\mathrm{H}_{\mathrm{E}}$ & $\mathrm{A}$ & $\mathrm{H}_{\mathrm{O}}$ & $\mathrm{H}_{\mathrm{E}}$ & A & \\
\hline MP144 & $0.558 *$ & 0.616 & 3.130 & 0.592 & 0.638 & 3.997 & $0.425^{*}$ & 0.640 & 4.705 & $0.31 *$ \\
\hline Pv9 & $0.579 *$ & 0.580 & 3.792 & 0.411 & 0.420 & 2.156 & $0.611^{*}$ & 0.757 & 4.846 & $0.857^{*}$ \\
\hline MP197 & $0.553^{*}$ & 0.547 & 3.094 & $0.554 *$ & 0.577 & 3.164 & 0.641 & 0.543 & 2.000 & 0.548 \\
\hline Ggu101 & $0.615^{*}$ & 0.673 & 3.732 & 0.586 & 0.614 & 3.659 & 0.449 & 0.471 & 3.857 & 0.762 \\
\hline MP247 & $0.224^{*}$ & 0.677 & 4.311 & $0.229 *$ & 0.589 & 4.038 & $0.306^{*}$ & 0.723 & 4.000 & $0 *$ \\
\hline MA1 & $0.606^{*}$ & 0.685 & 3.462 & $0.664 *$ & 0.673 & 3.457 & 0.722 & 0.714 & 3.907 & 0.607 \\
\hline $\mathrm{Tt} 1$ & 0.106 & 0.115 & 2.201 & 0.122 & 0.120 & 1.73 & $0.071 *$ & 0.356 & 1.800 & 0.100 \\
\hline MP200 & 0.474 & 0.410 & 3.030 & $0.467 *$ & 0.590 & 3.055 & 0.438 & 0.467 & 2.000 & 0.476 \\
\hline MP175 & 0.740 & 0.733 & 3.931 & 0.689 & 0.710 & 4.099 & 0.532 & 0.817 & 3.953 & 0.750 \\
\hline Overall & 0.495 & 0.560 & 3.409 & 0.479 & 0.548 & 3.262 & 0.466 & 0.610 & 3.452 & 0.490 \\
\hline
\end{tabular}

Table 4. Effective population size $\left(\mathrm{N}_{\mathrm{e}}\right)$ for each state and relative sample sizes (n) reported from linkage disequilibrium estimation at a lowest allele frequency of 0.02 with $95 \%$ confidence intervals (CI).

\begin{tabular}{ccccc} 
& West Virgina & Pennsylvania & New York & New Hampshire \\
\hline $\mathrm{N}_{\mathrm{e}}$ & $94.5(83.4-\infty)$ & $108.5(84.7-141.2)$ & $30.9(12.1-\infty)$ & $-14.2(-94.6-\infty)$ \\
$\mathrm{n}$ & 87 & 340 & 22 & 13 \\
\hline
\end{tabular}




\section{Figures}

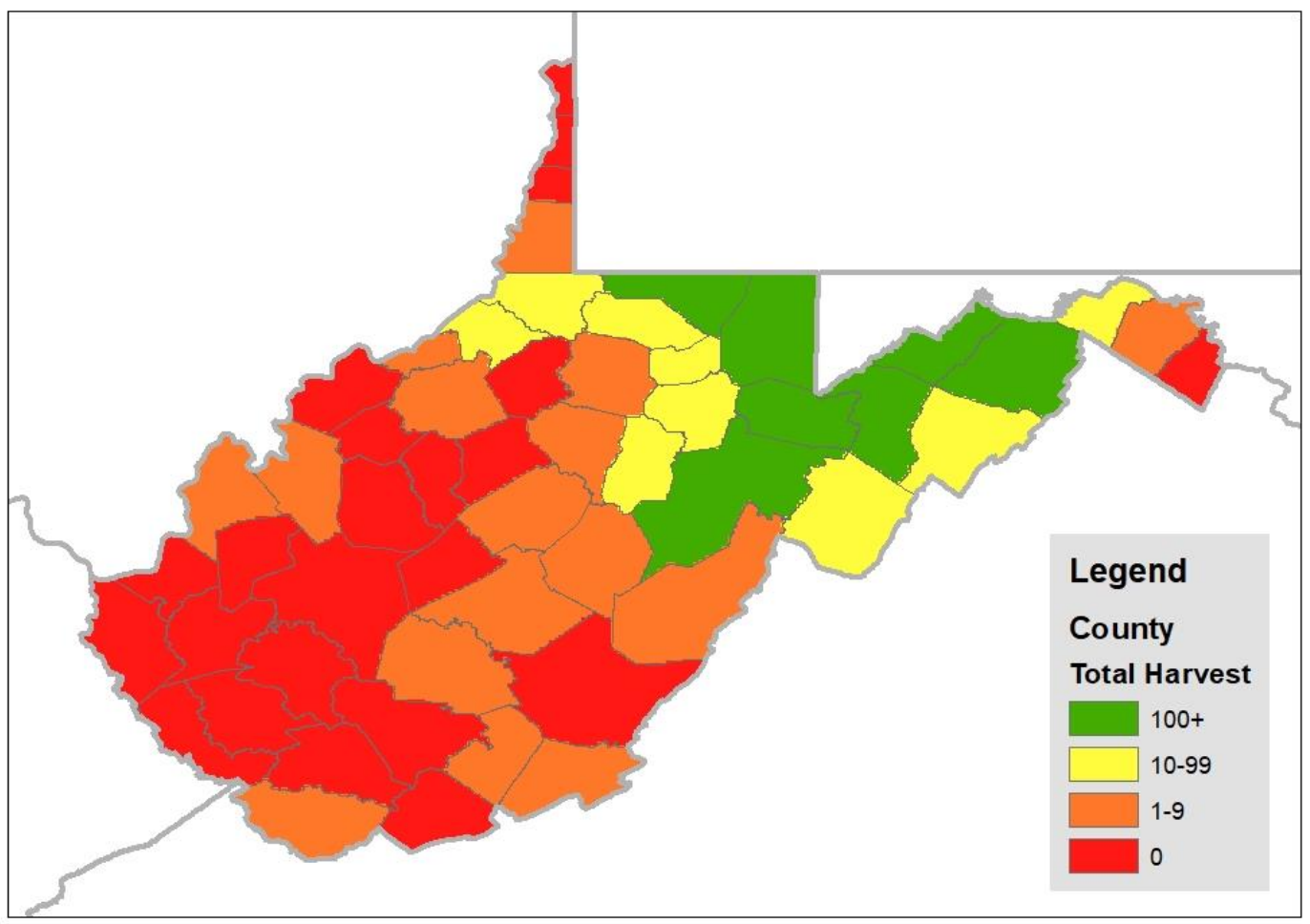

Figure 1. West Virginia county map representing the cumulative number of fishers harvested by WV trappers by county from 1972 to 2021. Sourced from West Virginia Division of Natural Resources (WVDNR). 


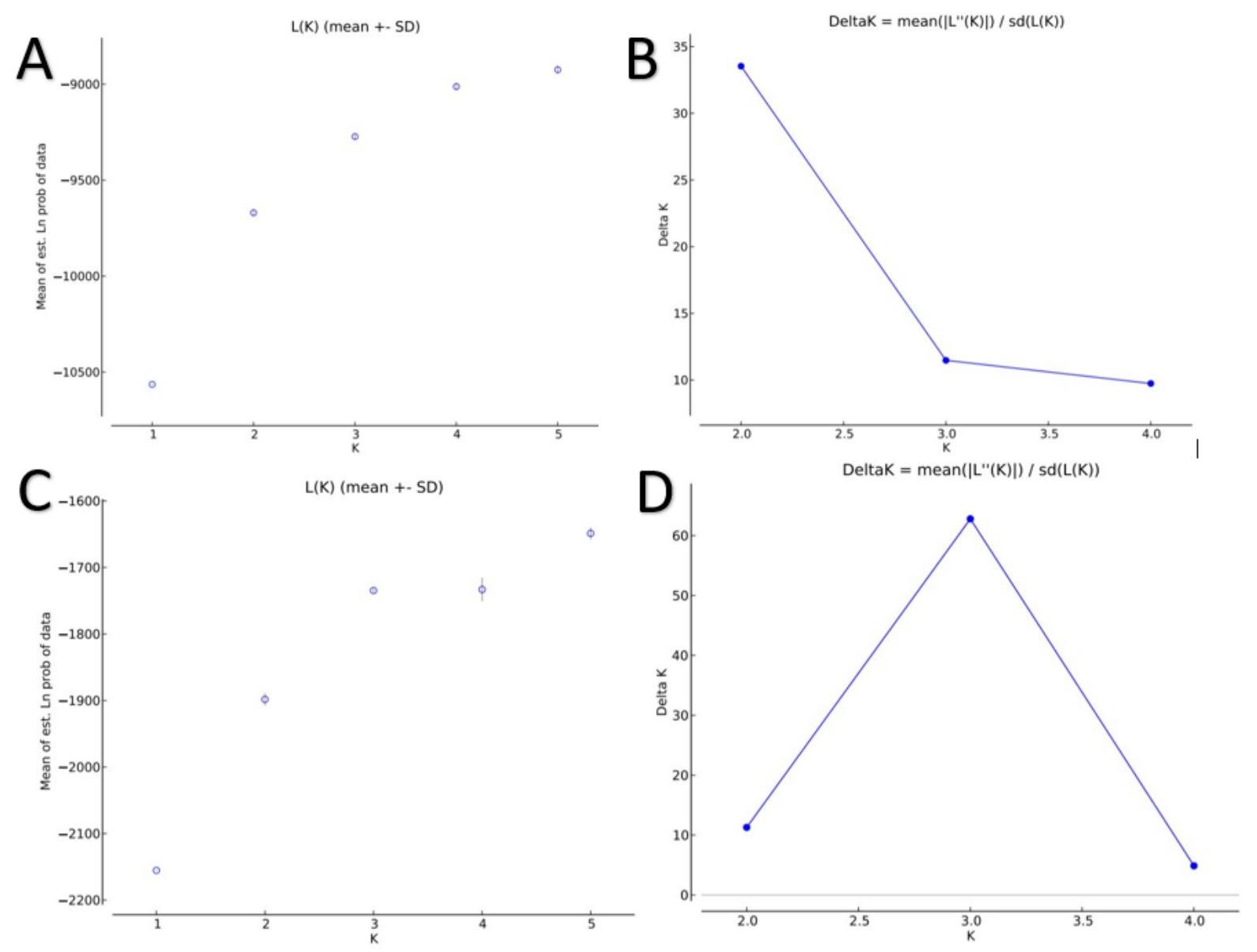

Figure 2. Graphic representation of estimated probability of data for each K value. A) Logarithm probability of K for within WV samples and C) across all samples (WV, PA, NY, NH) together. B) Delta K within WV samples and D) across all samples. 

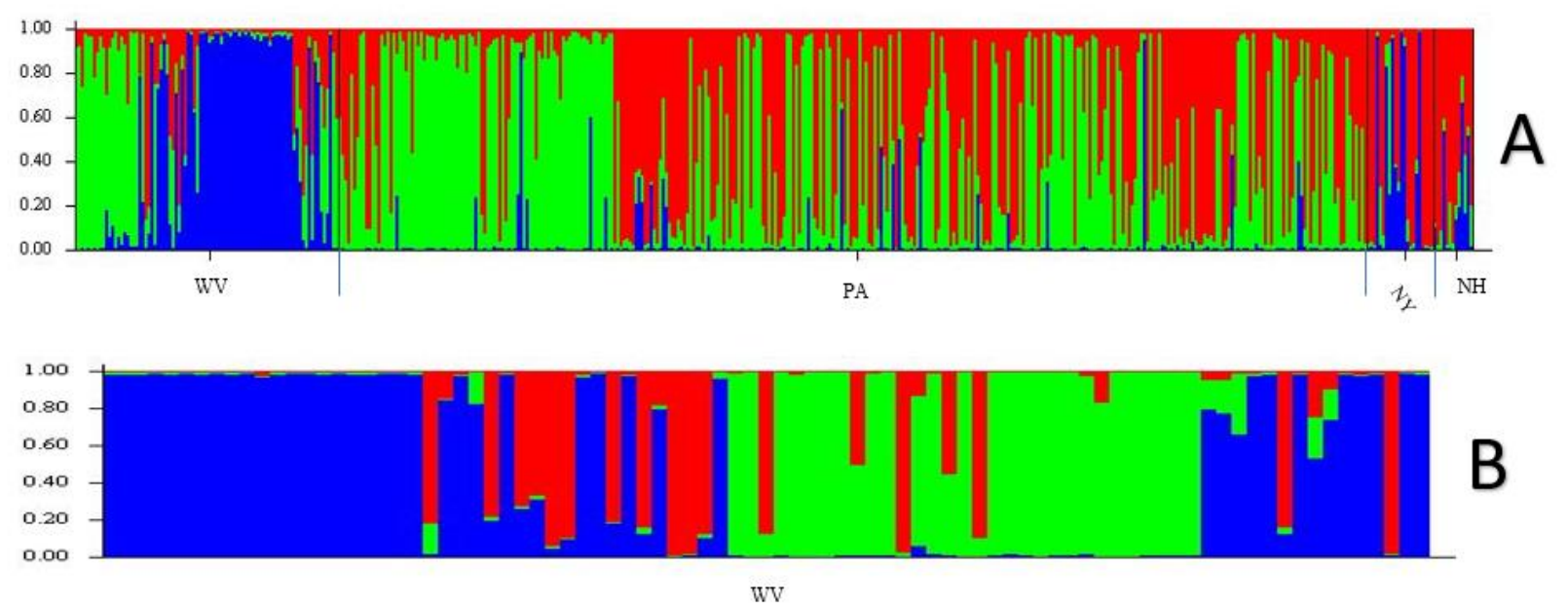

Figure 3. Individual memberships to clusters identified based on genetic data. A) Results from all four states (WV, PA, NY, NH) based on $\mathrm{K}=3$. B) Results limited to only WV samples based on $\mathrm{K}=3$. 


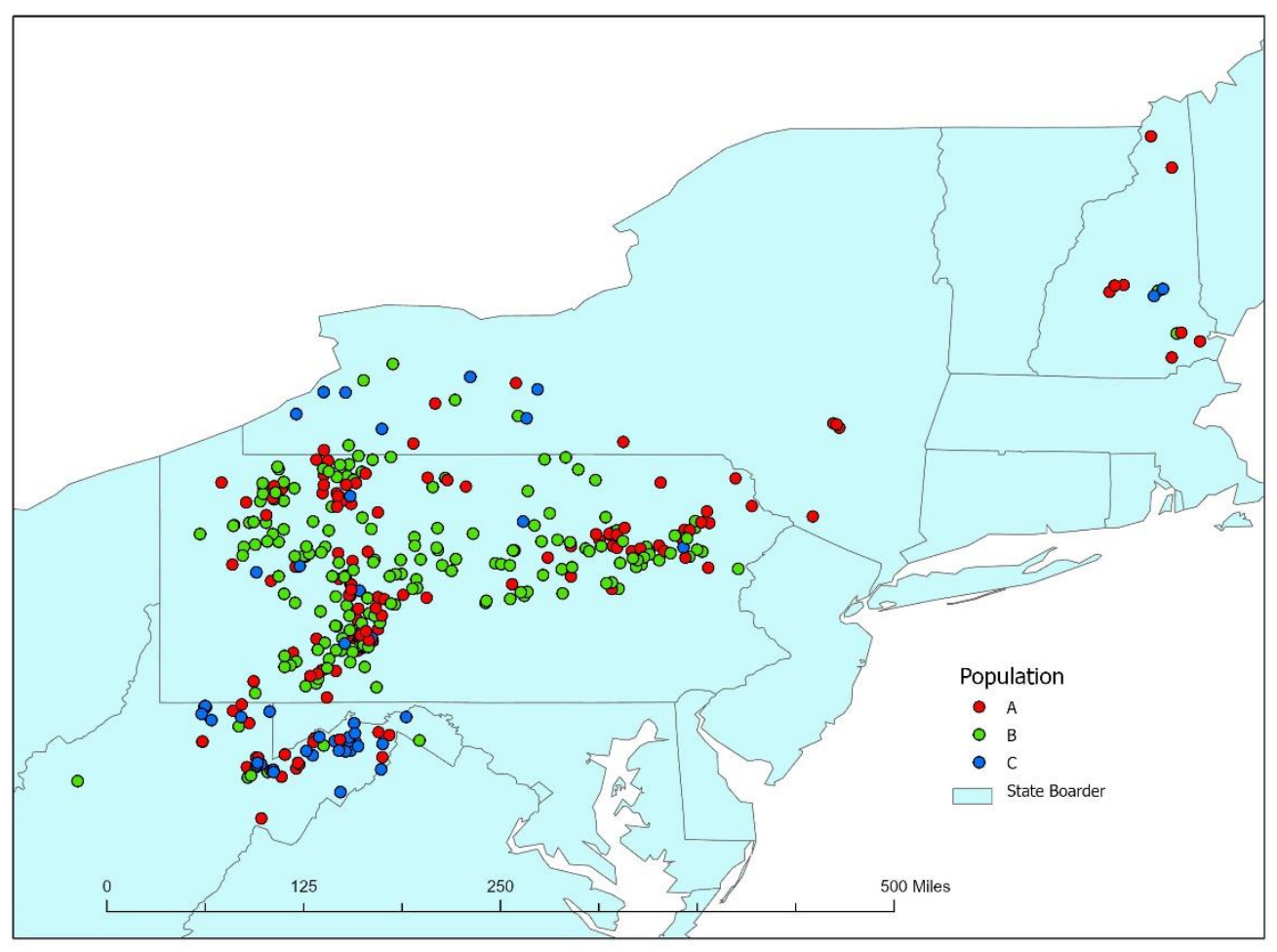

Figure 4. ArcGIS Pro map of all samples with location information $(n=459)$. Colored dots represent population percentage results from STRUCTURE. Samples were given population A (red), B (green), or C (blue) based on the highest population percentage of the three possible populations. 


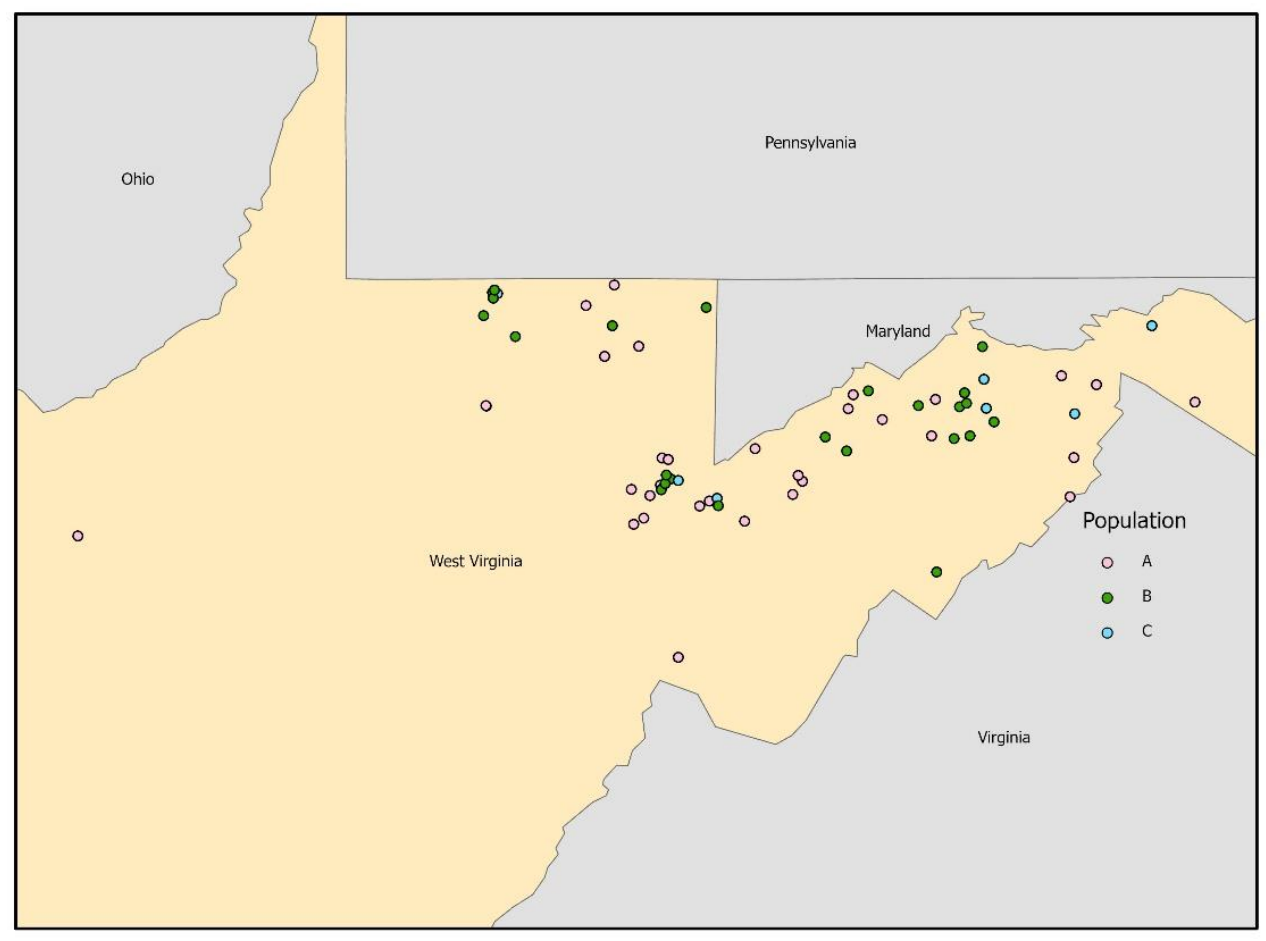

Figure 5. ArcGIS Pro map of West Virginia samples with location information $(n=87)$. Colored dots represent population percentage results from STRUCTURE. Samples were given population A (pink), B (green), or C (light blue) based on the highest population percentage of the three possible populations. 


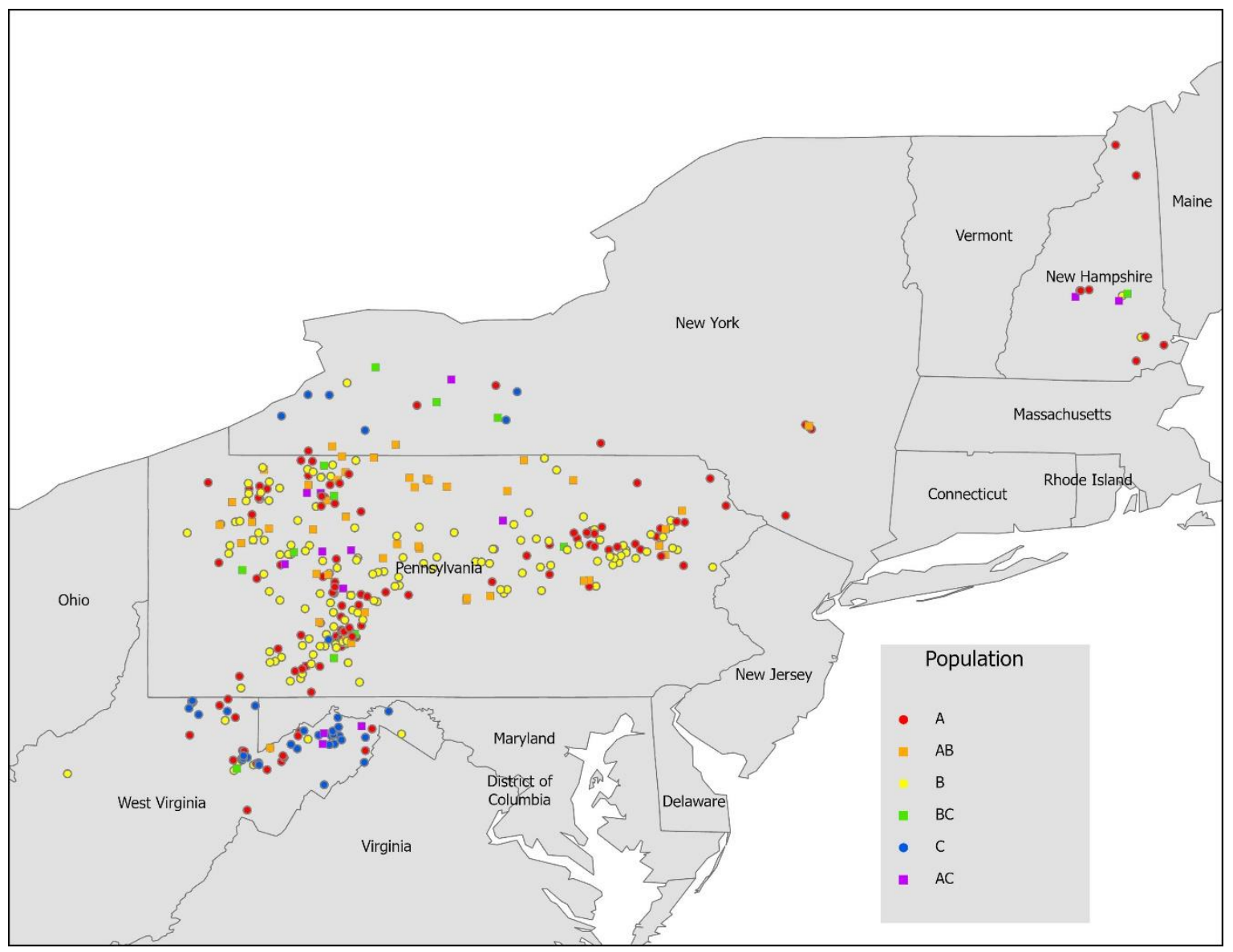

Figure 6. ArcGIS Pro map of all samples with location information $(n=459)$. Colored circles represent admixture population percentage results from STRUCTURE. Samples were given pure population A (red), B (yellow), or C (blue) based on $>0.8$ population percentage of the three STRUCTURE populations. Samples with $<0.8$ percentage were given combined of top two percentage represented as squares with $\mathrm{AB}$ (orange), $\mathrm{BC}$ (green), or $\mathrm{AC}$ (purple). 


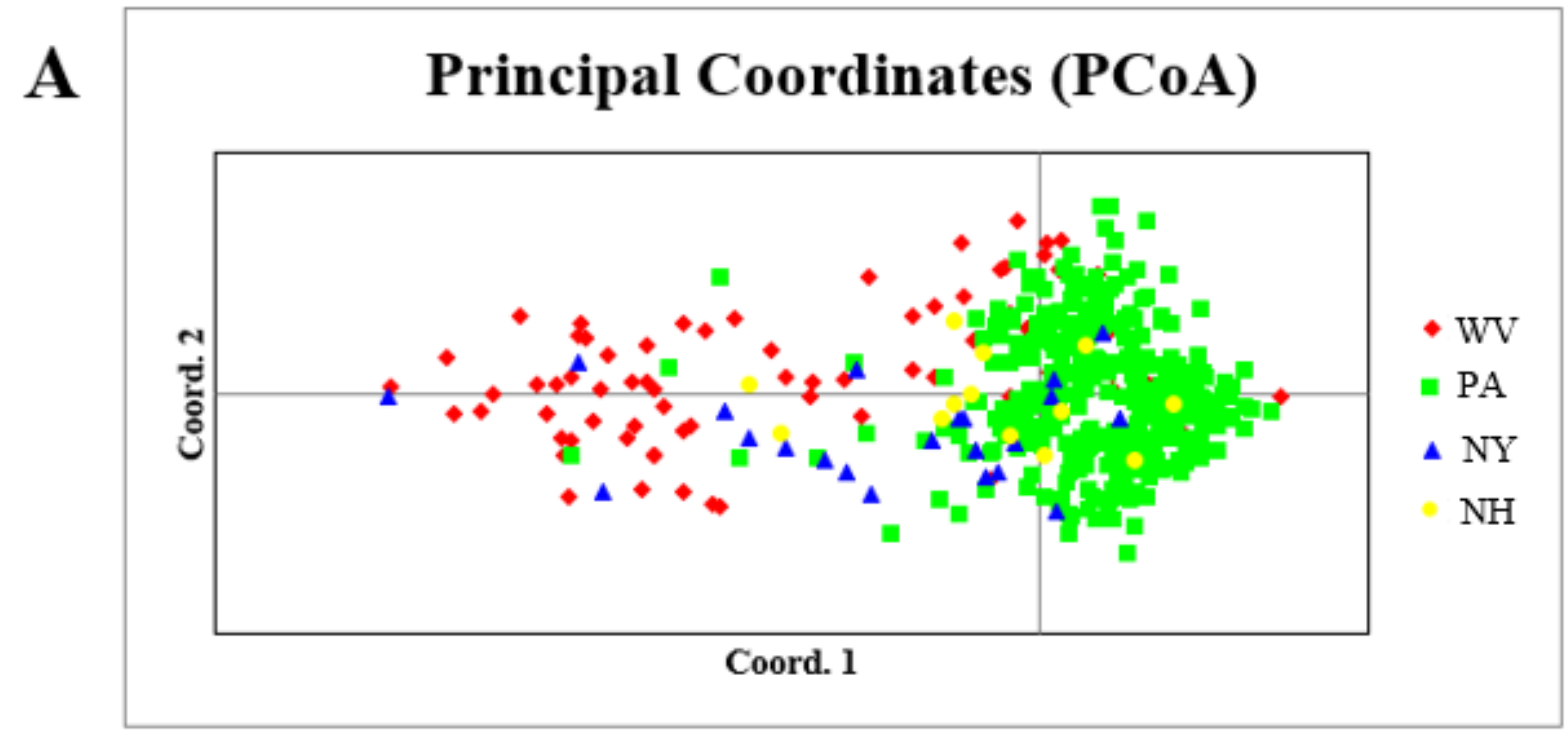

B

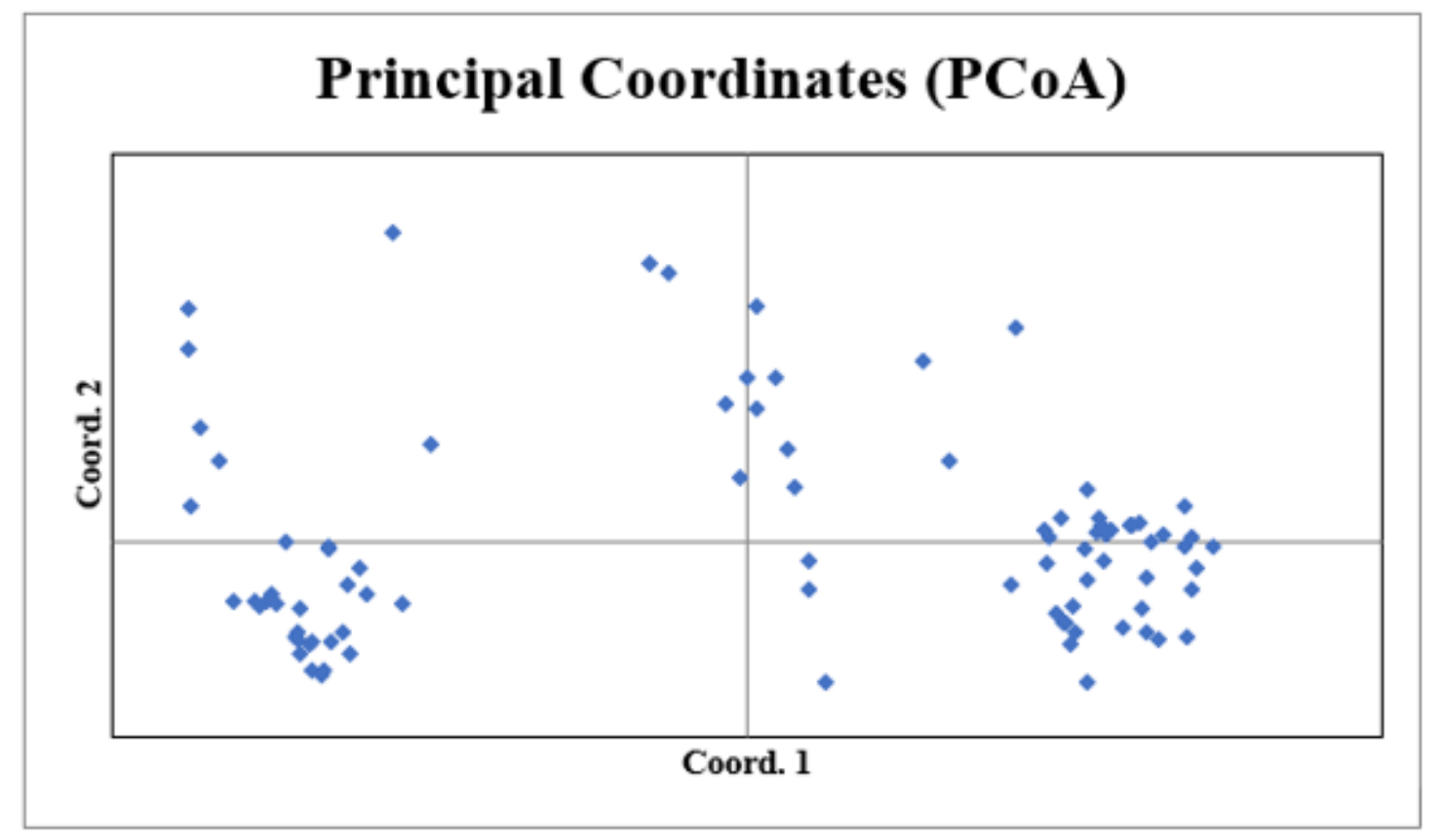

Figure 7. Graphic results of a Principal Coordinates Analysis (PCoA) from the GenAlEx package for Microsoft Excel. The principal coordinates optimize the representation of the squared pairwise distances between individuals $\mathbf{A}$ ) across all states and $\mathbf{B}$ ) within WV. 


\section{Principal Coordinates (PCoA)}

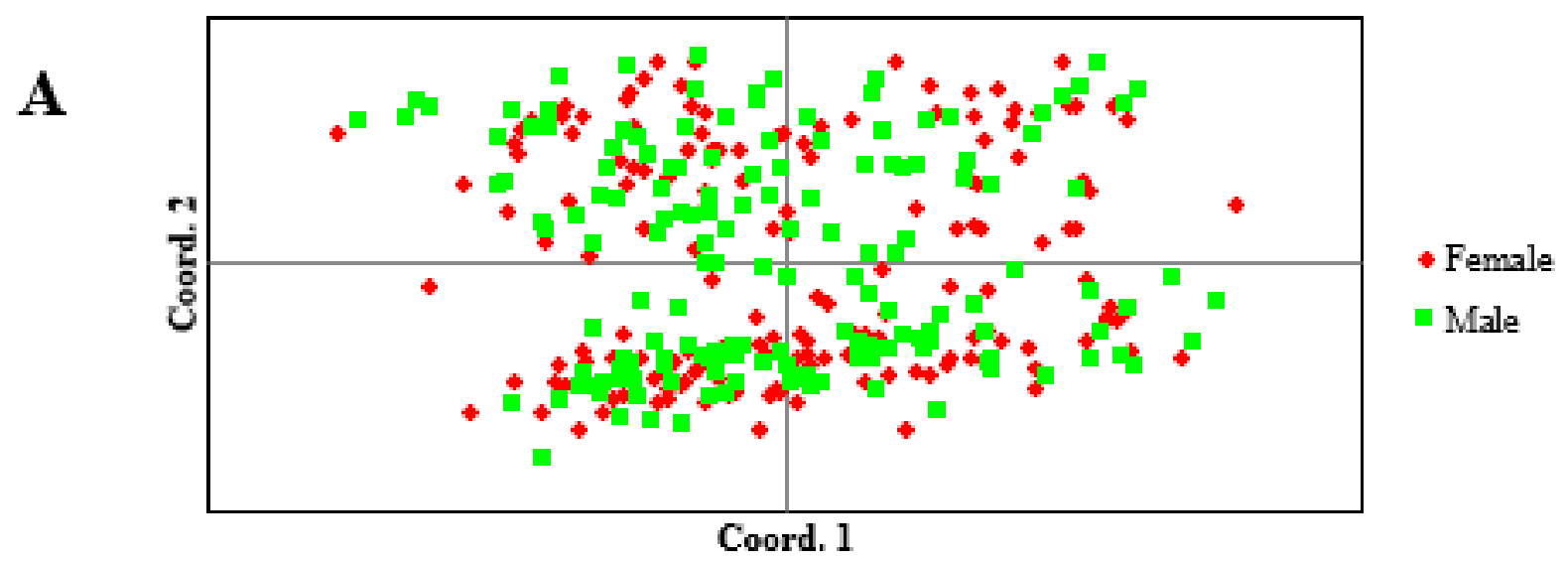

\section{Principal Coordinates (PCoA)}

B

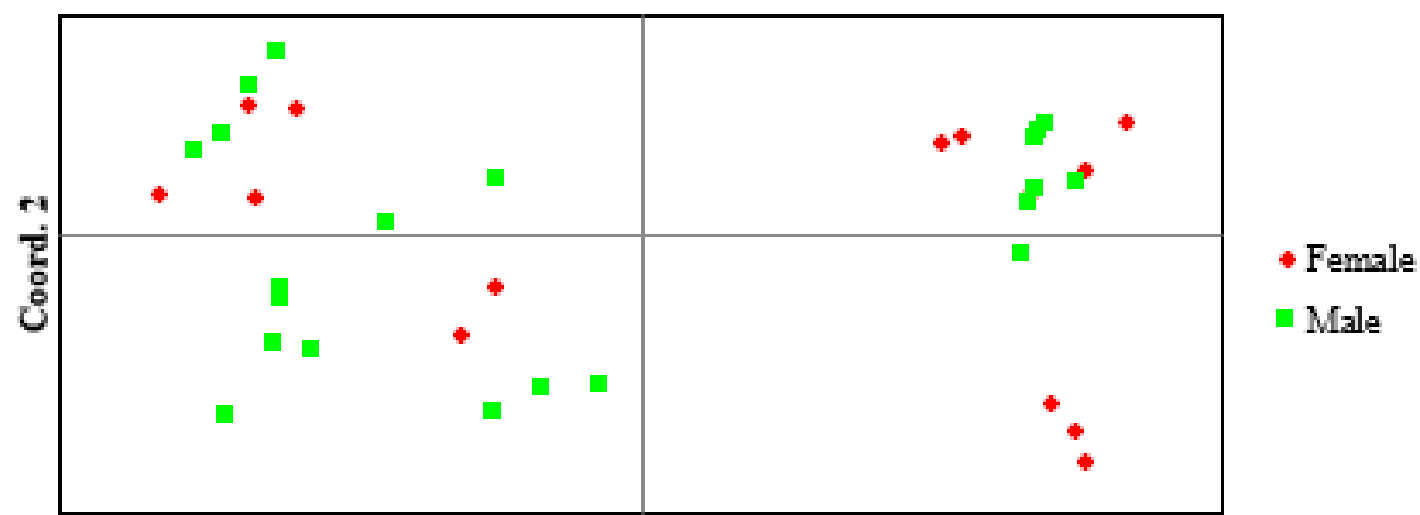

Coord. 1

Figure 8. Graphic results of a Principal Coordinates Analysis (PCoA) from the GenAlEx package for Microsoft Excel. The principal coordinates optimize the representation of the squared pairwise distances between sexes (Female or Male) within A) Pennsylvania B) West Virginia. 